\title{
Morphodynamics and sedimentary structures of bedforms under supercritical-flow conditions: New insights from flume experiments
}

\author{
MATTHIEU J.B. CARTIGNY*1 , DARIO VENTRA*, GEORGE POSTMA* and \\ JAN H. VAN DEN BERG* \\ *Faculty of Geosciences, Utrecht University, P.O. box 80021, 3508TA, Utrecht, The Netherlands \\ (E-mail: m.cartigny@noc.ac.uk)
}

Associate Editor - Jeremy Venditti

\begin{abstract}
Supercritical-flow phenomena are fairly common in modern sedimentary environments, yet their recognition and analysis remain difficult in the stratigraphic record. This fact is commonly ascribed to the poor preservation potential of deposits from high-energy supercritical flows. However, the number of flume data sets on supercritical-flow dynamics and sedimentary structures is very limited in comparison with available data for subcritical flows, which hampers the recognition and interpretation of such deposits. The results of systematic flume experiments spanning a broad range of supercritical-flow bedforms (antidunes, chutes-and-pools and cyclic steps) developed in mobile sand beds of variable grain sizes are presented. Flow character and related bedform patterns are constrained through time-series measurements of bed configurations, flow depths, flow velocities and Froude numbers. The results allow the refinement and extension of some widely used bedform stability diagrams in the supercritical-flow domain, clarifying in particular the morphodynamic relations between antidunes and cyclic steps. The onset of antidunes is controlled by flows exceeding a threshold Froude number. The transition from antidunes to cyclic steps in fine to medium-grained sand occurs at a threshold mobility parameter. Sedimentary structures associated with supercritical bedforms developed under variable aggradation rates are revealed by means of combining flume results and synthetic stratigraphy. The sedimentary structures are compared with examples from field and other flume studies. Aggradation rate is seen to exert an important control on the geometry of supercritical-flow structures and should be considered when identifying supercritical bedforms in the sedimentary record.
\end{abstract}

Keywords Antidunes, chutes-and-pools, cyclic steps, flume experiments, hydraulic jump, supercritical flow.

\section{INTRODUCTION}

Primary sedimentary structures reflect the complex interactions between sediment load and carrying flows, as widely demonstrated by research in fluid mechanics, sedimentary geology and engineering in natural, experimental and numerical settings (Kennedy, 1963; Leeder, 1983; Allen, 1985; Best, 1993, 1996). Bedforms and sedimentary structures formed in unidirectional subcritical,

\footnotetext{
${ }^{1}$ Present address: National Oceanography Centre, European Way, SO14 3ZH, Southampton, Hampshire, UK
} 
oscillatory and combined flows are fairly wellunderstood after a long history of experimental research, and owing to their ubiquitous presence and recognition in present-day sedimentary environments and in the rock record. However, significant gaps remain in current knowledge of the origin and dynamics of bedforms produced by unidirectional supercritical flows (see reviews by Yagishita, 1992, and Fielding, 2006). Flume experiments and numerical modelling have shown consistent bedform patterns arising from supercritical flows over sandy beds. Numerous observations from modern environments show that such phenomena are common (e.g. McKee et al., 1967; Waters \& Fisher, 1971; Augustinus, 1980; Barwis \& Hayes, 1985; Wells \& Dohrenwend, 1985; Blair, 1987; Langford \& Bracken, 1987; Alexander \& Fielding, 1997; Carling \& Breakspear, 2007; Duller et al., 2008).

The sedimentary record, therefore, should preserve many examples of structures and facies formed by such flows, but their recognition and analysis remain sparse in the literature. This sparsity is ascribed to the supposedly poor preservation potential of deposits from ephemeral, highenergy events. However, because documented flume data sets on the sedimentology of supercritical flows over sand beds are limited in number (Middleton, 1965; Jopling \& Richardson, 1966; Simons \& Richardson, 1966; Hand, 1974; Cheel, 1990; Best \& Bridge, 1992; Alexander et al., 2001; Yokokawa et al., 2010), the inability to identify and interpret the resulting deposits might actually be due to insufficient understanding of these structures and facies (Fielding, 2006).

This paper aims to: (i) describe the results of systematic flume experiments in the Eurotank Flume Laboratory (Utrecht University), exploring changes in flow character and related bedform patterns with increasing flow energy over mobile sand beds of different grain sizes; (ii) expand the classical bedform stability diagrams in order to include a wider range of supercritical-flow bedforms; (iii) study grain-size effects on the formation of supercritical bedforms; (iv) interpret morphodynamic relations between different types of supercritical-flow bedforms; and (v) describe and analyse the sedimentary structures, comparing them with previous flume experiments and outcrop studies. Since bedforms developing from supercritical flow have received relatively little attention from sedimentologists, the following section provides a concise introductory review of terminology, supercritical-flow processes (for example, types of hydraulic jumps, surges and roll waves) and their interactive relation with bedforms as a function of Froude or Vedernikov numbers.

\section{SUPERCRITICAL FLOWS AND THEIR BEDFORMS: GENERAL OVERVIEW}

In supercritical flows, inertia dominates over gravity; this is expressed by the Froude number $\left(F r=\frac{U}{\sqrt{g h}}\right)$ exceeding unity, where $U$ is the flow velocity, $h$ is the flow depth and $g$ is the acceleration of gravity. Such flows can be further characterized (Fig. 1) by: (i) a Reynolds number $\left(R e=\frac{U h}{V}\right)$, where $v$ is kinematic viscosity), distinguishing between turbulent and laminar flows (Robertson \& Rouse, 1941); and (ii) the Vedernikov number, which distinguishes stable uniform flows from unstable non-uniform ones (Chow, 1959; Koloseus \& Davidian, 1966). The Vedernikov number for wide channels is defined as $V e=x F r$ (Chow, 1959), where the coefficient $x$ describes the dependency of flow velocity on flow depth as used in the uniform flow formula (Chézy, $x=1 / 2$ or Manning, $x=2 / 3$ ). This statement implies a transition from stable to unstable flow at $F r=1.5$ to 2 . In stable, uniform flows $(V e<1)$, free-surface waves (waves on the upper interface of the flow) will be suppressed, while in unstable uniform flows $(V e>1)$ free-surface waves are amplified, leading to breaking waves that develop into roll waves (periodic surges) at higher Froude numbers (Cornish, 1910; Koloseus \& Davidian, 1966; Brock, 1967; Karcz \& Kersey, 1980). Stable versus unstable flow behaviour has been well-studied for laminar conditions (Karcz \& Kersey, 1980; Devauchelle et al., 2010a,b) and for flows over non-erodible beds (Brock, 1967).

A similar transition between stable and unstable flow has been found for turbulent supercritical flow over mobile beds, where the onset of unstable flow triggers the formation of freesurface waves and antidunes, while periodic fluctuating flows at higher Froude numbers are accompanied by chutes-and-pools and cyclic steps (Guy et al., 1966; Alexander et al., 2001; Spinewine et al., 2009). The influence of an erodible bed on the transition between stable supercritical flows and unstable supercritical turbulent flows is still poorly constrained; in particular the morphodynamic relations between supercritical flows and bedforms typical for these flows are poorly understood. 


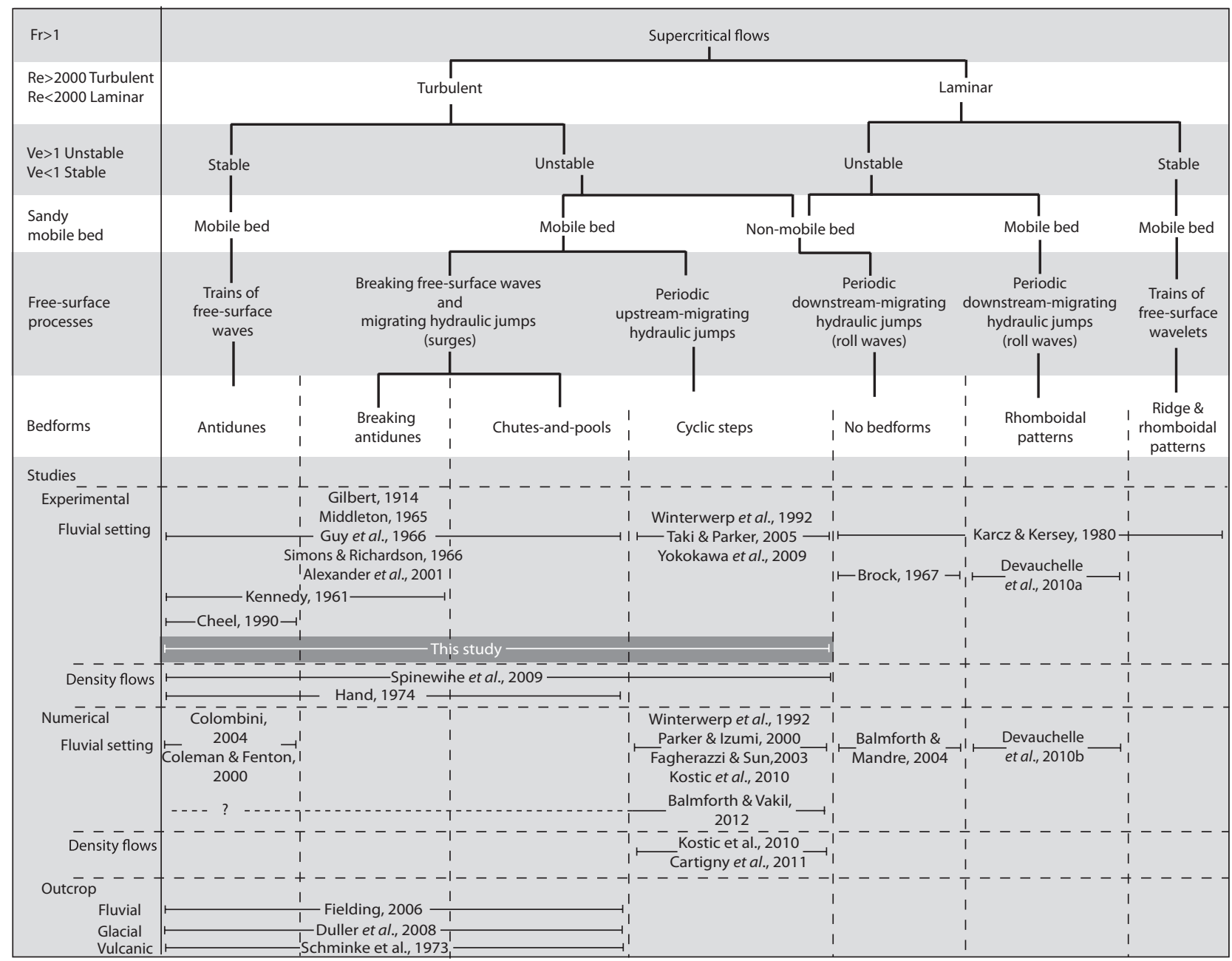

Fig. 1. Conceptual subdivision of supercritical-flow phenomena on the basis of Reynolds number and Vedernikov number; the mobility of the sedimentary bed provides an additional criterion.

\section{Characteristics of supercritical flow}

Free surfaces of turbulent supercritical flows are characterized by waves, hydraulic jumps and surges (Brock, 1967; Alexander et al., 2001; Taki \& Parker, 2005). Waves at the free surface of supercritical flows are triggered by internal flow instabilities (Jeffreys, 1925; Vedernikov, 1945, 1946). If wavelengths considerably exceed the flow depth, the velocity of wave propagation relative to flow velocity is given by $\sqrt{g h}$ (e.g. Lighthill, 1978). The ratio of flow velocity to wave propagation velocity (expressed by the Froude number) determines whether waves can migrate upstream. This fact implies that if a flow is supercritical in its upstream portion and subcritical downstream, waves in the subcritical portion of the flow can travel upstream until they reach the point where flow velocity equals the velocity of wave propagation $(F r=1)$. At this point, a physical transition between supercritical and subcritical flow forms a hydraulic jump, characterized by an abrupt increase in flow depth and a decrease in flow velocity, accompanied by substantial energy loss. If fluid and/or sediment entrainment over the jump is neglected, then the strength of hydraulic jumps is defined by the ratio of the outgoing subcritical-flow depth behind the jump and incoming supercritical-flow depth in front of the jump (conjugated depths), and can be related to the energy loss $(\Delta H)$ over the hydraulic jump by solving a mass and momentum balance over the incoming and outgoing flows (Belanger, 1828; Fig. 2A).

Experiments have shown that the geometric configuration of hydraulic jumps varies with their strength (Bradley \& Peterka, 1955; Chow, 
HYDRAULIC JUMP STRENGTH AND TYPE

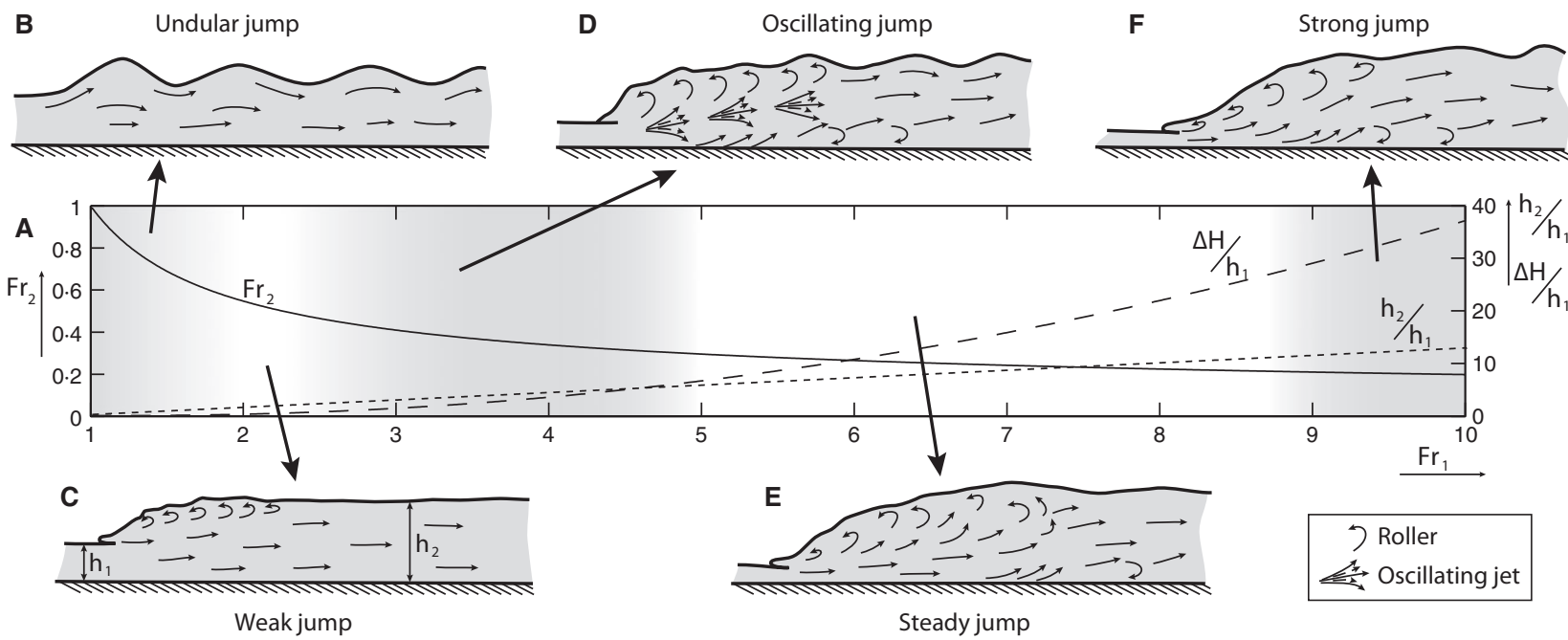

HYDRAULIC JUMP LOCATION

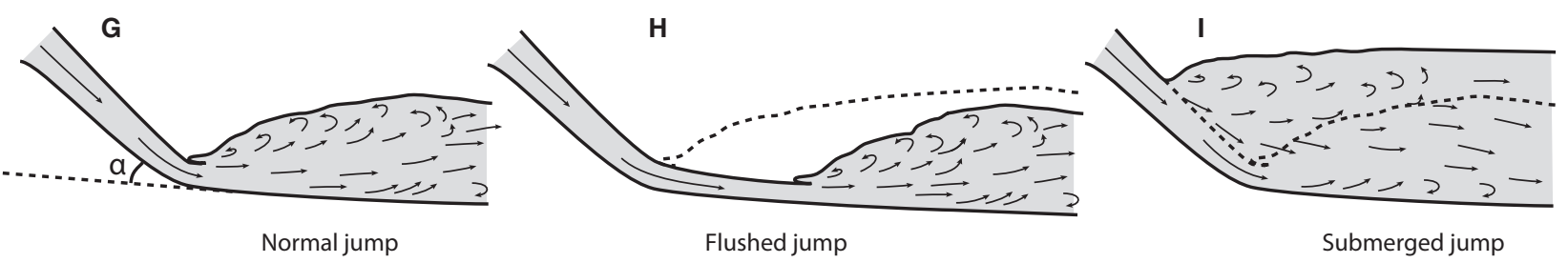

Fig. 2. Geometric and dynamic configurations of hydraulic jumps. (A) The central diagram shows the theoretical relations between outgoing Froude number $\left(\mathrm{Fr}_{2}\right)$, the dimensionless energy loss expressed in metres of water column $\left(\Delta H / h_{1}\right)$ and the ratio of conjugated depths $\left(h_{2} / h_{1}\right)$ as a function of the incoming Froude number $\left(F r_{1}\right)$. Experiments have shown that different kinds of hydraulic jumps (B) to (F) occur at different incoming Froude numbers (Bradley \& Peterka, 1955; Chow, 1959; Lennon \& Hill, 2006). (G) Hydraulic jumps occurring at a slope break (normal jump, kinematic energy equals potential energy), (H) downstream of a slope break (flushed jump, kinematic > potential), or (I) upstream of the slope break (submerged jump, kinematic < potential). More detailed classifications can be found in Rajaratnam (1967) and Hager (1992).

1959; Lennon \& Hill, 2006). Undular jumps (Fig. 2B) form at conjugated depth ratios close to unity (Fig. 2A), corresponding to minor energy losses, and are typical for incoming Froude numbers between 1 and 1.7 (although there is variability within these values, depending on channel geometry and bed roughness; Montes, 1986). As the incoming Froude number increases, the leading wave of the undular jump starts to break and recirculating cells (rollers) form at the free surface (Fig. 2C; weak jump). Turbulence and internal friction within rollers are responsible for most of the energy dissipation at the hydraulic jump. At incoming Froude numbers between 2 and 4, hydraulic jumps become very unstable (Fig. 2D); the incoming flow (jet) tends to detach from the bed (MacDonald et al., 2009) and allows the formation of recirculation cells between bed and main flow, strongly reducing local shear stress at the bed in oscillating jumps. Further increases in the Froude number of the incoming supercritical flow stabilize the jump morphology (Fig. 2E and F) and trigger even greater turbulence, vorticity and energy dissipation (Long et al., 1991). Hydraulic jumps occurring at slope breaks ( $\alpha$; see Fig. 2G) have been classified according to their position relative to the slope break (Fig. 2G to I; Rajaratnam, 1967; Hager, 1992).

Where there is an imbalance between upstream and downstream forces, hydraulic jumps tend to migrate, and are referred to as surges. Surges are said to be positive if the wave front advances, and negative if it retreats (irrespective of the general flow direction; cf. Chanson, 2002, 2009). Periodic positive surges propagating in the flow direction over fixed or poorly mobile beds under unstable supercritical flows are called roll waves or Cornish waves (Cornish, 1910; Brock, 1967). The experiments 
reported here were carried out over mobile sand beds, which led supercritical bedforms to suppress the formation of roll waves (Balmforth \& Vakil, 2012).

\section{Supercritical-flow bedforms}

Supercritical flows over mobile sediment beds lead to a great variety of bed morphologies (Gilbert, 1914; Simons et al., 1965; Allen, 1982), depending on flow conditions and sediment grain size (Guy et al., 1966). Bedforms in unidirectional flow are traditionally divided into upper flow-regime and lower flow-regime (Simons et al., 1965), depending on Froude number, flow viscosity and grain mobility (Van den Berg \& Van Gelder, 1998; Van den Berg \& Nio, 2010). Upper flow-regime bedforms are commonly considered to be characterized by in-phase relations between the free water surface and the bed interface (Simons et al., 1965; Middleton \& Southard, 1984), although recent research has shown that in-phase relations do not hold for all kinds of supercritical-flow bedforms (Alexander et al., 2001; Yokokawa et al., 2009). An alternative subdivision can be made between free-surfacedependent and free-surface-independent bedforms (Middleton \& Southard, 1984).

Experiments in unidirectional open-channel flows have consistently shown the development of characteristic bedform sequences with increasing flow energies: ripples, dunes, upper-stage plane bed, antidunes, chutes-and-pools and cyclic steps (e.g. Gilbert, 1914; Simons et al., 1965; Alexander et al., 2001; Taki \& Parker, 2005). In the case of pipe flows, which lack a free surface, experiments have shown that only part of this sequence forms, spanning from ripples to upperstage plane beds (Newitt et al., 1955; Fredsøe \& Engelund, 1975; Saunderson, 1982). Hence, ripples, dunes and upper-stage plane beds can form independently of a free surface, whereas antidunes, chutes-and-pools and cyclic steps are tied to the presence of a free surface and to the associated development of waves, surges and hydraulic jumps. Free-surface-dependent bedforms formed under supercritical flow include: antidunes, chutes-and-pools and cyclic steps.

Antidunes are bedforms geometrically and dynamically in-phase with non-breaking surface waves, and show variable rates of upstream or downstream migration depending on flow energy and grain size (Gilbert, 1914; Kennedy, 1961; Middleton, 1965; Simons et al., 1965; Hand, 1974; Langford \& Bracken, 1987; Alexander \&
Fielding, 1997; Alexander et al., 2001; Carling \& Schvidchenko, 2002; Yokokawa et al., 2010). Experimental observations often describe the development of 'trains' of antidunes (Kennedy, 1961; Simons et al., 1965; Guy et al., 1966; Yokokawa et al., 2010) that tend to migrate downstream, independent of the direction of migration of the individual bedforms; antidunes at the upstream end of the train are scoured away by the incoming flow, while new antidunes form at the downstream end (Kennedy, 1961).

At higher Froude numbers, in-phase relations between bed and free surfaces no longer hold, as surface waves start to steepen and break. Bedforms associated with these breaking surface waves have been termed breaking antidunes (Simons \& Richardson, 1966) because of the water surface wave that breaks over the antidune. Kennedy (1961) showed a positive correlation between Froude number and wave breaking, and also observed a threshold value in the ratio of wave height over wave length (0.14) required to trigger the breaking of surface waves. The combination of these observations suggests a positive correlation between wave amplitude and Froude number. This wave breaking leads to cyclic destruction and regeneration of antidune bedforms (Gilbert, 1914; Kennedy, 1961; Middleton, 1965; Guy et al., 1966; Blair, 1987; Langford \& Bracken, 1987). The observed processes during wave breaking differ widely, depending on the interaction between the dynamics of the surges and the bed morphology: (i) breaking waves leading to positive surges forming new antidunes upstream of the old ones (Middleton, 1965); (ii) breaking waves forming new antidunes downstream of the old ones (Guy et al., 1966); (iii) breaking waves leading to stretches of flat bed separating adjacent antidunes (Kennedy, 1961; Schumm et al.,1982); and/or (iv) antidunes disappearing without wave breaking (Kennedy, 1961).

Chutes-and-pools consist of reaches where the flow rapidly accelerated (chutes), ending in a hydraulic jump followed by a long pool where the flow is tranquil, but accelerating (Simons et al., 1965). Chutes-and-pools have been observed to migrate upstream (Simons et al., 1965; Guy et al., 1966) with velocities close to or higher than those of accompanying antidunes (Middleton, 1965). Chutes have also been shown to be followed downstream by antidunes associated with breaking surface waves (Middleton, 1965; Guy et al., 1966) or large standing waves (Guy et al., 1966) closely resembling those 
observed in the field observations of Langford \& Bracken (1987) and backwash ripples on beaches (Broome \& Komar, 1979). Hand (1974) described how breaking antidune waves form in a pool just downstream of a hydraulic jump before a new set of antidunes form to replace the pool. Alexander et al. (2001) observed chute-and-pool structures being separated by areas of relative plane bed.

Cyclic steps are very similar to chute-and-pool structures and have been described as a series of slowly upstream-migrating steps, where each step is manifested as a zone of steeply dropping supercritical flow bounded at the downstream end by a hydraulic jump (Parker, 1996). Similar repeating step-like phenomena have also been described by Winterwerp et al. (1992) as cascade of upstream migrating sand bars with nearly horizontal terraces covered by subcritical flows. The distinction of cyclic steps with chutes-andpools is not always clear, because cyclic steps also involve an erosive lee side (chute) and a depositional stoss side (pool). Following Fukuoka et al. (1982), Taki \& Parker (2005) proposed to distinguish chute-and-pool structures as a limiting case of cyclic steps for which the steepest bed slope realized just upstream of the hydraulic jump is still rather mild.

Experiments have shown that all free-surfacedependent bedforms develop in a similar manner at equal Froude numbers in density flows like turbidity currents (Hand, 1974; Spinewine et al., 2009). In such settings, cyclic steps are morphologically associated with sediment waves (Fildani et al., 2006; Kostic \& Parker, 2006; Lamb et al., 2008; Kostic et al., 2010; Cartigny et al., 2011; Kostic, 2011). Coarse-grained sediment waves in submarine canyons have also been interpreted as antidunes (Normark et al., 1980) or cyclic steps (Cartigny et al., 2011) formed by turbidity currents in a manner similar to the experiments of Spinewine et al. (2009).

The morphodynamic relations between different types of supercritical-flow bedforms are still poorly constrained, mainly because most experimental work so far has focused on single bedform types or covered only part of the bedform spectrum (Fig. 1). The study presented here considers a wide range of free-surface-dependent bedforms in fine to medium sand, from antidunes to cyclic steps, with a focus on the morphodynamic relations between such bedforms and their sedimentological signatures in turbulent flows.

\section{METHODS}

Experiments were conducted at the Eursotank Flume Laboratory (Utrecht University) using a flume (12 m long, $0.48 \mathrm{~m}$ wide and $0.6 \mathrm{~m}$ deep) in which water and sediment were both recirculated. The flume was filled with $c a 1.5 \mathrm{~m}^{3}$ of sediment, resulting in a sedimentary bed of $c a$ $0 \cdot 2 \mathrm{~m}$ deep. Twenty-one runs (Table 1 ) of varying discharges were carried out on sand beds of wellsorted fine to medium sands $\left(D_{50}=160 \mu \mathrm{m}\right.$, $D_{50}=265 \mu \mathrm{m}$ and $\left.D_{50}=350 \mu \mathrm{m}\right)$. Flow was re-circulated for several hours at the start of each run, to establish a low time-averaged sedimentation rate and to check that no scours to the non-erodible floor of the flume occurred. Most runs lasted approximately $1 \mathrm{~h}$, allowing for development and migration of a substantial number of bedforms.

Discharge was measured by an electromagnetic discharge meter in the recirculation pipe. A monochrome camera was positioned at the side of the flume at $c a 7 \mathrm{~m}$ downstream of the inlet, where it captured bulk flow configurations and sedimentary processes through the glass wall at a rate of 10 pictures per second. Panoramic overviews of bedforms were obtained by collecting vertical pixel columns from each image, and subsequently plotting them against time. Image analysis techniques were used to detect the level of the bed and water interface on each image to determine the flow depth. By combining flow depth from the images and discharge measurements, time series of flow velocity and related parameters were established, thereby neglecting any non-uniformity in the discharge over the length of the flume.

To facilitate comparisons of runs and previously published data, several other parameters were calculated (Table 1). Velocity and water depth time series were combined to establish Froude-number time series. The $50^{\text {th }}$ (median) and $90^{\text {th }}$ percentiles from the Froude time series are indicated as $F_{50}$ and $F_{90}$ in Table 1. Following the $\mathrm{Fr}_{90}$ definition, also peak velocities $\left(U_{90}\right)$ and minimum flow depth $\left(h_{10}\right)$ are determined to calculate the (grain) mobility parameter $\left(\theta_{90}^{\prime}\right)$ used by Van den Berg \& Van Gelder (1993) in their bedform stability diagram as:

$$
\theta_{90}^{\prime}=\frac{\rho U_{90}^{2}}{\left(\rho_{s}-\rho\right)\left(C_{90}^{\prime}\right)^{2} D_{50}}
$$

where $\rho_{s}$ and $\rho$ are the density of quartz and water, respectively, $D_{50}$ is the median grain size and $D_{90}$ is the $90^{\text {th }}$ percentile grain size, and 
Table 1. Experimental conditions for individual experimental runs. Subscripts indicate the percentile of time-series measurements: 50 equals median and 90 equals ninetieth percentile (value surpassed by $10 \%$ of the measurements). Bed level and water level time series have not been constructed for Runs 21 to 23 , and therefore overall sedimentation rates are not available (NA) for these runs.

\begin{tabular}{|c|c|c|c|c|c|c|c|c|c|c|}
\hline $\begin{array}{l}\text { Run } \\
\#\end{array}$ & $\begin{array}{l}\text { Median } \\
\text { grain } \\
\text { size } \\
(\mu \mathrm{m})\end{array}$ & $\begin{array}{l}\text { Specific } \\
\text { discharge } \\
\left(\mathrm{m}^{2} \mathrm{~h}^{-1}\right)\end{array}$ & $\begin{array}{l}\mathrm{U}_{50} \\
\left(\mathrm{~m} \mathrm{~s}^{-1}\right)\end{array}$ & $\begin{array}{l}\mathrm{h}_{50} \\
(\mathrm{~m})\end{array}$ & $\begin{array}{l}\mathrm{Fr}_{50} \\
(-)\end{array}$ & $\begin{array}{l}\operatorname{Fr}_{90} \\
(-)\end{array}$ & $\begin{array}{l}\text { Mobility } \\
\text { parameter } \\
\left(\theta_{90}\right)(-)\end{array}$ & $\begin{array}{l}\text { Grain-shear } \\
\text { stresses }\left(\tau_{90}^{\prime}\right) \\
\left(\mathrm{kg} \mathrm{m}^{-1} \mathrm{~s}^{-2}\right)\end{array}$ & $\begin{array}{l}\text { Sedimentation } \\
\text { rate overall } \\
\left(\mathrm{mm} \mathrm{h}^{-1}\right)\end{array}$ & Bedform \\
\hline 1 & 160 & $122 \cdot 3$ & $0 \cdot 45$ & $0 \cdot 071$ & 0.95 & $2 \cdot 10$ & $2 \cdot 97$ & $7 \cdot 69$ & $-4 \cdot 1$ & Cyclic steps \\
\hline 2 & 160 & $153 \cdot 5$ & $0 \cdot 80$ & 0.051 & $1 \cdot 16$ & $1 \cdot 58$ & $2 \cdot 48$ & $6 \cdot 42$ & $-0 \cdot 1$ & Chute-and-pool \\
\hline 3 & 160 & $319 \cdot 8$ & $1 \cdot 03$ & $0 \cdot 084$ & $1 \cdot 10$ & $1 \cdot 32$ & $2 \cdot 20$ & $5 \cdot 70$ & $0 \cdot 1$ & $\begin{array}{l}\text { Unstable } \\
\text { antidunes }\end{array}$ \\
\hline 4 & 160 & $460 \cdot 8$ & 0.83 & $0 \cdot 149$ & $0 \cdot 69$ & $0 \cdot 70$ & $0 \cdot 76$ & $1 \cdot 97$ & $0 \cdot 1$ & Upper flat bed \\
\hline 5 & 160 & $280 \cdot 2$ & $0 \cdot 74$ & $0 \cdot 101$ & $0 \cdot 88$ & $1 \cdot 51$ & $5 \cdot 43$ & $14 \cdot 06$ & $-13 \cdot 5$ & Cyclic steps \\
\hline 6 & 160 & $275 \cdot 8$ & $0 \cdot 84$ & 0.087 & 0.97 & $1 \cdot 63$ & $3 \cdot 41$ & $8 \cdot 83$ & $2 \cdot 7$ & Cyclic steps \\
\hline 7 & 160 & $414 \cdot 0$ & $1 \cdot 03$ & $0 \cdot 107$ & $1 \cdot 00$ & $1 \cdot 33$ & $2 \cdot 57$ & $6 \cdot 66$ & $3 \cdot 3$ & Antidunes \\
\hline 9 & 350 & $257 \cdot 5$ & $0 \cdot 78$ & $0 \cdot 088$ & $1 \cdot 15$ & $2 \cdot 07$ & $6 \cdot 21$ & $35 \cdot 18$ & $-8 \cdot 5$ & Cyclic steps \\
\hline 10 & 350 & $375 \cdot 4$ & $1 \cdot 25$ & $0 \cdot 080$ & $1 \cdot 33$ & $1 \cdot 82$ & $2 \cdot 97$ & $16 \cdot 83$ & $-4 \cdot 0$ & Chute-and-pool \\
\hline 11 & 350 & $337 \cdot 5$ & $1 \cdot 10$ & $0 \cdot 083$ & $1 \cdot 22$ & $1 \cdot 31$ & $1 \cdot 22$ & $6 \cdot 91$ & -0.5 & Antidunes \\
\hline 12 & 350 & $337 \cdot 5$ & $1 \cdot 23$ & 0.074 & $1 \cdot 31$ & $2 \cdot 04$ & $4 \cdot 13$ & $23 \cdot 40$ & $-1 \cdot 2$ & Chute-and-pool \\
\hline 13 & 350 & $307 \cdot 1$ & 0.94 & $0 \cdot 087$ & 1.03 & $1 \cdot 78$ & $5 \cdot 95$ & $33 \cdot 71$ & $1 \cdot 4$ & Cyclic steps \\
\hline 14 & 350 & $302 \cdot 3$ & $1 \cdot 05$ & 0.076 & $1 \cdot 16$ & $1 \cdot 61$ & $2 \cdot 68$ & $15 \cdot 18$ & $-0 \cdot 2$ & Chute-and-pool \\
\hline 15 & 350 & $336 \cdot 5$ & $1 \cdot 17$ & 0.077 & $1 \cdot 31$ & $2 \cdot 06$ & $6 \cdot 14$ & $34 \cdot 78$ & $-1 \cdot 3$ & Cyclic steps \\
\hline 16 & 350 & $324 \cdot 2$ & $1 \cdot 06$ & $0 \cdot 081$ & $1 \cdot 29$ & $2 \cdot 27$ & $8 \cdot 82$ & $49 \cdot 97$ & $6 \cdot 6$ & Cyclic steps \\
\hline 18 & 265 & $237 \cdot 5$ & 0.98 & 0.064 & $1 \cdot 22$ & $1 \cdot 41$ & $1 \cdot 36$ & $5 \cdot 83$ & $-0 \cdot 2$ & Antidunes \\
\hline 19 & 265 & $268 \cdot 8$ & $1 \cdot 09$ & $0 \cdot 067$ & 1.41 & $1 \cdot 82$ & $2 \cdot 15$ & $9 \cdot 22$ & $0 \cdot 4$ & Antidunes \\
\hline 20 & 265 & $297 \cdot 9$ & $1 \cdot 14$ & $0 \cdot 070$ & $1 \cdot 39$ & $1 \cdot 83$ & $2 \cdot 50$ & $10 \cdot 72$ & $-6 \cdot 9$ & Chute-and-pool \\
\hline 21 & 265 & $304 \cdot 2$ & $1 \cdot 03$ & $0 \cdot 080$ & $1 \cdot 26$ & $2 \cdot 17$ & $3 \cdot 50$ & $15 \cdot 01$ & NA & Cyclic steps \\
\hline 22 & 265 & $220 \cdot 8$ & 0.88 & $0 \cdot 068$ & $1 \cdot 07$ & $1 \cdot 15$ & $0 \cdot 91$ & $3 \cdot 90$ & NA & Antidunes \\
\hline 23 & 265 & $300 \cdot 0$ & $1 \cdot 04$ & 0.077 & $1 \cdot 33$ & $2 \cdot 14$ & $3 \cdot 59$ & $15 \cdot 40$ & NA & Chute-and-pool \\
\hline
\end{tabular}

with the ninety-percentile grain-roughness Chézy coefficient $\left(C_{90}^{\prime}\right)$ defined as:

$$
C_{90}^{\prime}=18 \log \left(\frac{4 h_{10}}{D_{90}}\right)
$$

Dimensional peak grain-shear stresses were calculated as proposed by Van Rijn (1984a):

$$
\tau_{90}^{\prime}=g \rho \frac{u_{90}^{2}}{\left(C_{90}^{\prime}\right)^{2}}
$$

In their bedform stability diagrams Van Rijn (1984b) and Van den Berg \& Van Gelder (1993) used the dimensionless grain size $D$ * as defined by Bonnefille (1963):

$$
D_{*}=\left\{\frac{\left(\rho_{s}-\rho\right) g}{\rho v^{2}}\right\}^{1 / 3}
$$

where $v$ is the kinematic viscosity of the fluid.

Time-average sedimentation rates (Table 1) were determined by fitting a linear least-square trend line on the measured bed-level time series, and hence show the sedimentation rate on a time range of at least one order of magnitude larger than the time required for a single bedform to migrate past the measuring point. To study the wave lengths of the different bedforms, spectral density estimates were made of the time series of bed level and free surface by a Welch overlapping segmented averaging method (Welch, 1967). The time series were divided into 14 50\%-overlapping Hanning-windowed segments before applying a discrete Fourier analyses. Confidence intervals were calculated by assuming a chi-squared distribution with 70 equivalent degrees of freedom (Emery \& Thomson, 1998).

The evolution of sedimentary structures was studied by capturing the geometry of bed interfaces over the entire image width through time; successive geometries were projected on top of each other to trace the internal structure of the evolving bedform by superposition of different bed interfaces through time. The resulting association of timelines did not necessarily correspond to the internal geometry of sedimentary structures; if no internal stratification was formed, timeline successions would not actually 
appear in the real deposits. If a new bed interface cut into a previous one due to local erosion, the eroded portion was removed and replaced by the outline of the new bed interface.

Time series of bed interfaces were also used to construct sedimentary sequences by application of a synthetic aggradation technique (Corea, 1978; Southard et al., 1990; Dumas et al., 2005). This technique plots bed interfaces in a similar way to that described above, but it performs synthetic aggradation by shifting the sedimentary interface upward before analysing successive image frames. The upward shift corresponds to an imposed synthetic aggradation rate, here corresponding to values of $0 \cdot 03,0.12$ and $0.24 \mathrm{~mm} \mathrm{~s}^{-1}$. Although the technique neglects the influence of additional sediment carried by the flow to accomplish such an aggradation rate, it provides qualitative insights on the variability of vertical sequences of sedimentary structures as a function of combined aggradation rates and bedform types. A comparison between the direct observations and the synthetic aggradation result can be seen in four movies in the supporting information (Movies S1 to S4).

\section{RESULTS: MORPHODYNAMICS AND INTERNAL SEDIMENTARY STRUCTURES OF SUPERCRITICAL BEDFORMS}

The experiments showed the evolution of antidunes to cyclic steps with increasing flow energy. To clarify the terminology used here, which has conflicting meanings in the literature, a bedform classification scheme based both on existing terminology and on the observations is presented here.

Figure 3 shows four vertically exaggerated, schematized, upstream-migrating bedform configurations formed with continuously increased Froude numbers, from (A) to (D), based on the observations presented here. The first stage (Fig. 3A) consisted of antidunes with non-breaking in-phase surface waves. To distinguish these from antidunes with breaking surface waves, they are here called stable antidunes. The term stable does not exclude migration or amplitude fluctuations of the waves in either time or space. In contrast, unstable antidunes (Fig. 3B), are characterized by the occurrence of breaking surface waves (in time or space) and the associated cycles of antidune formation, wave breaking, destruction and rebuilding. At higher energy levels, a long-wavelength bedform (compared to antidunes) dominated the morphology, consisting of upstream migrating chutes that end downstream in a series of unstable antidunes. These features and their related hydraulic jumps and surges are here called chutes-and-pools (Fig. 3C). Only if the chutes were followed by a persistent stable hydraulic jump, where stable again does not exclude migration or strength fluctuations in either in time or space, are bedforms here referred to as cyclic steps (Fig. 3D). The morphodynamics and internal two-dimensional architecture, derived from synthetis stratigraphy, are described below.

\section{Stable antidunes}

\section{Morphodynamics}

Long trains of stable antidunes (Run 11) are characterized by surface waves fully in-phase with undulations developed at the sediment bed interface (Fig. 3A; Movie S1). Stable antidunes migrate upcurrent by erosion of the downstream side (lee side) and deposition at the upstream side (stoss side). Downcurrent migration was not observed during any of the runs performed. Figure $4 \mathrm{~A}$ shows six photographs from the monochrome camera. Black lines represent the evolution of laminae (successive bed interfaces without synthetic aggradation) and set boundaries through time. Their stacking shows that the bed aggraded under higher amplitude antidunes $\left(t_{1}-t_{5}\right)$, and degraded under lower amplitude antidunes at the tail of a full antidune train $\left(t_{6}\right)$.

Figure 4B shows the antidunes as they migrated and passed the camera over the first $1200 \mathrm{~s}$ of the run. The position of the images shown in Fig. 4A is indicated by their time values $\left(t_{1}, t_{2}\right.$, etc.). The panoramic image shows that the bed interface and the free surface were in-phase, and that the amplitudes of the perturbations on both interfaces remained proportional. The amplitude of the antidunes varied with time; high-amplitude antidunes were generally followed by series of increasingly lower amplitude antidunes, giving rise to bedform trains.

Although the corresponding Froude numbers plotted in Fig. 4C remained above one, their values varied over individual antidunes. Highamplitude antidunes associated with strong fluctuations in Froude numbers were subsequently damped and lower amplitude antidunes were established until the onset of the next series of high-amplitude antidunes. When considering a series of several antidunes, the average Froude 


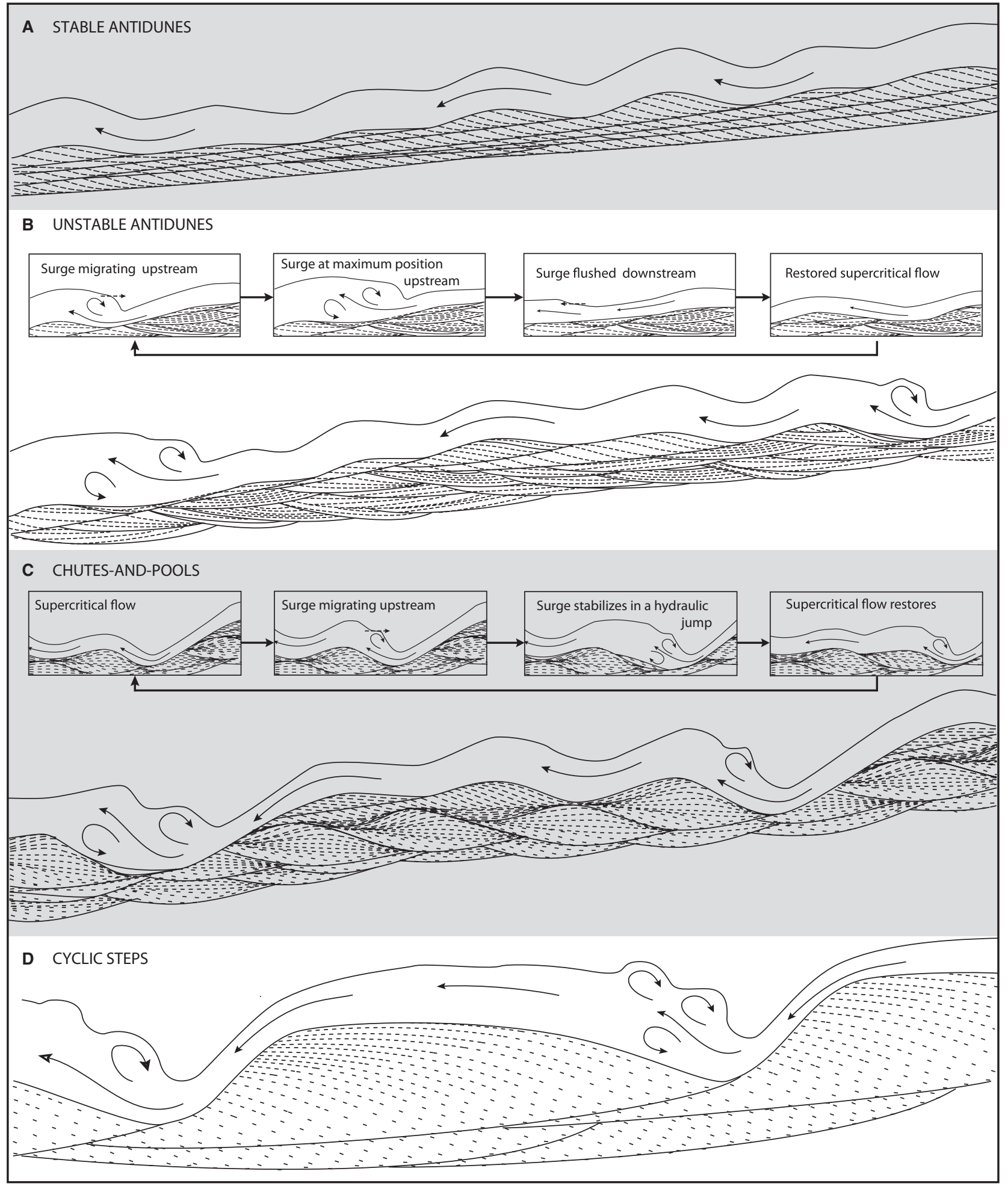

Fig. 3. Representative idealized overview of four stages in unidirectional supercritical flows, corresponding to the development of the four kinds of bed configurations presented and defined here (flow directed from right to left; vertical scale exaggerated for clarity). Additional insets for unstable antidunes and chutes-and-pools illustrate the dynamics of associated cyclic processes. 
Run $11, Q=337.5\left[\mathrm{~m}^{2} / \mathrm{h}\right]$, coarse sand
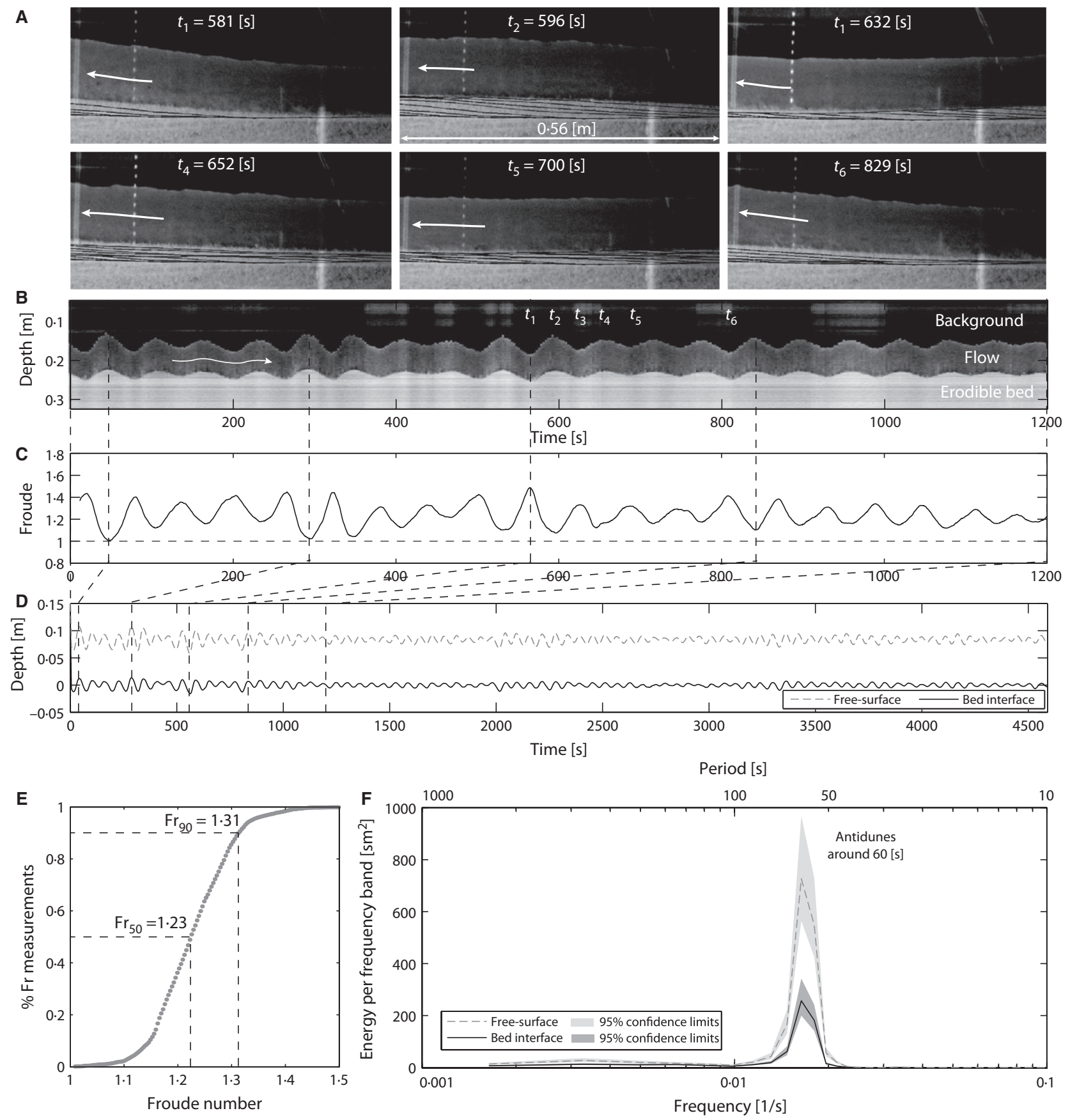

Fig. 4. Morphodynamics of stable antidune bedforms. (A) Photographs of the flow through the flume sidewall. Time, $t$, indicated in white, corresponds to the times on the horizontal axes of graphs in (B), (C) and (D); flow direction is to the left and internal structures are indicated by black timelines. (B) Time series of vertical pixel rows extracted from the first 12000 images, plotted as a spatial panorama of the sediment bed interface and the free surface (note that flow direction is here from right to left, due to upstream migration). The darkest area corresponds to the background, the lightest horizontally striped area to the erodible bed and the grey area in between represents the flowing fluid. (C) Froude numbers time series at a fixed position, corresponding to the panoramic view in (B). Critical Froude number is shown by the dashed line. (D) The bed interface (continuous black) and free surface (dashed grey) comparable to (B), but over the full length of the run. Correlation between the first 1200 $\mathrm{s}$ and the rest of the run is indicated by vertical dashed lines. (E) Distribution of Froude number measured over the entire run; stippled lines show the median and $90^{\text {th }}$ percentile of the Froude number distribution. (F) Plot of the spectrum of the bed interface (continuous black) and the free flow surface (dashed grey). 
number correlates negatively with the height of the bed surface (Fig. 4A to C). Observations over the length of the flume showed that antidunes changed their aspect ratio both in time and space.

The characteristics of the full run are shown in the remaining panels. In Fig. 4D, the sediment bed interface (continuous black) and the flow surface (dashed grey) are plotted for the entire run (45900 data points, $4590 \mathrm{~s}$, ca $75 \mathrm{~min}$ ). This time series shows the consistent in-phase relation between bed interface and flow surface over longer period fluctuations in wave amplitude. Most antidune trains show cycles of abrupt increase in amplitude, followed by a gradual decrease (Fig. 4D; 300, 500, 850 and $2000 \mathrm{~s}$ ); however, the antidune train centred on $3500 \mathrm{~s}$ shows a gradual increase and decrease. From the spectral analysis (Fig. 4F), it is evident that undulations with a periodicity of $c a$ $60 \mathrm{~s}$, which correspond to antidunes, dominate the spectrum. Amplitude fluctuations of longer periodicity, which would characterize differences in amplitude of subsequent antidune trains, are not recognizable in this analysis. Figure 4E plots the distribution of Froude number time series and the $50^{\text {th }}$ and $90^{\text {th }}$ percentile.

\section{Observed bedform architecture}

Superimposed on the overall sedimentation rate, which was kept as low as possible (here $-0.5 \mathrm{~mm} \mathrm{~h}^{-1}$ ), sedimentary architectures result from differential aggradation and erosion of different portions of the sediment interface on shorter time scales, controlled by the formation and migration of antidunes. The connection between the process and the internal evolution of antidune deposits is highlighted by dark lines in Fig. 4A. As expected from counter-current migration, each antidune leaves behind a stack of backsets whose preservation depended primarily on the amplitude of successive antidunes reworking the sediment top, and secondarily on the rate of aggradation. Longer period bed undulations (trains of antidunes) induce first aggradation (stacking basal structures of high-amplitude antidunes), then degradation (as antidunes progressively reduce in amplitude). High-amplitude antidunes thus formed thicker backsets, with a maximum of approximately one-third of the antidune amplitude (see images at $t_{1}, t_{2}, t_{3}$ ). Afterwards, lower amplitude antidunes left much thinner sets $\left(t_{4}, t_{5}\right)$, and eventually the whole deposit was reworked by the successive high-amplitude antidunes $\left(t_{6}\right)$.
Synthetic bedform architecture

The resulting architecture, shown in Fig. 5B to $\mathrm{D}$, was obtained by the synthetic aggradation technique, and hence was not observed directly during the run. The top panel (Fig. 5A) shows the coupled evolution of the free surface and of the underlying depositional interface (see also Fig. 4D). The lower panels show internal architecture obtained at different synthetic aggradation rates (vertical scale not distorted; except Fig. 5E). Timelines of bed configuration are in time increments of $4 \mathrm{~s}$, within the same time framework as along the horizontal axis of the top panel.

The overall structure is given by stacked lamina sets with subhorizontal to gently inclined boundaries and a generally conformable geometry (see also the vertically exaggerated drawing in Fig. 3A). Internally, subhorizontal to low-angle backset laminae (dipping upcurrent), show lowangle to tangential terminations to the lower set boundary, depending on the sinusoidal geometry of the forming antidune. The succession is composed of bundles of lamina sets, each corresponding to progressive sedimentation from a train of antidunes; most bundles are characterized by a thinning-upward trend due to the decreasing amplitude of antidunes within a train (for example, the train of antidunes at $c a 0$ to $250 \mathrm{~s}$, indicated by the grey square).

The geometry of each lamina is strongly dependent on the preserved set thickness. Thin sets preserve only the lower portions of laminae, merging with the basal set boundary at a very low angle; consequently, preserved lamination shows a subhorizontal to very low-angle dip upstream. The structures of very thin or only partially preserved lamina sets resemble planeparallel lamination. In thicker sets, the upper portions of single laminae, which dip at higher angles, were preserved more frequently; the resulting backset geometry is thus much more evident because the average upcurrent dip of laminae is distinctly higher.

Aggradation rate is another variable that controls the preservation of lamina sets, and thus the internal geometry of the whole deposit. At relatively high aggradation rates (Fig. 5B), superimposed lamina sets are more distinctly recognizable due to their greater thickness and better preservation. Thicker lamina sets imply: (i) an overall higher dip of backset laminae, as noted above, although this also depends on the antidune amplitude; (ii) greater lateral continuity for 
A Interface of Run 11 for the first 1200 seconds

Depth $[\mathrm{m}]$

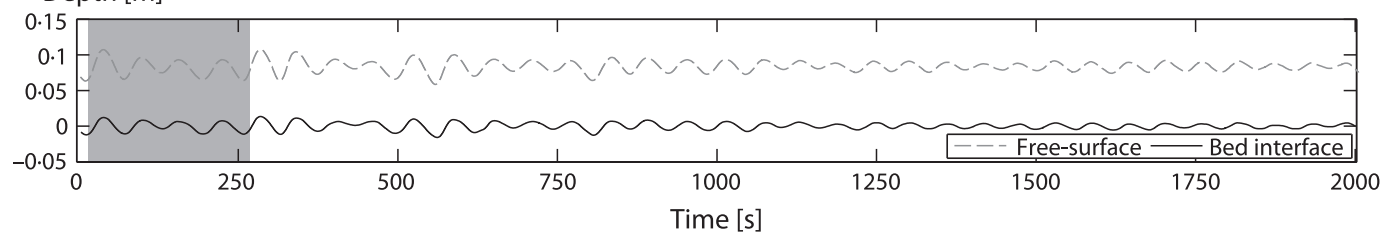

B Deposits formed during the first 500 seconds, with a synthetic aggradation rate of $0.24 \mathrm{~mm} \mathrm{~s}^{-1}$ Time $[s]$

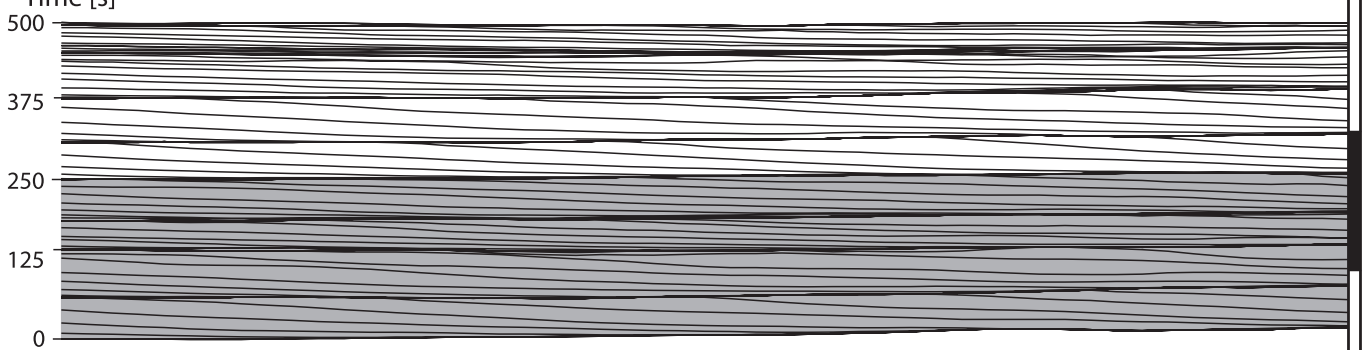

Flow direction

C Deposits formed during the first 1000 seconds, with a synthetic aggradation rate of $0.12 \mathrm{~mm} \mathrm{~s}^{-1}$ Time $[\mathrm{s}]$

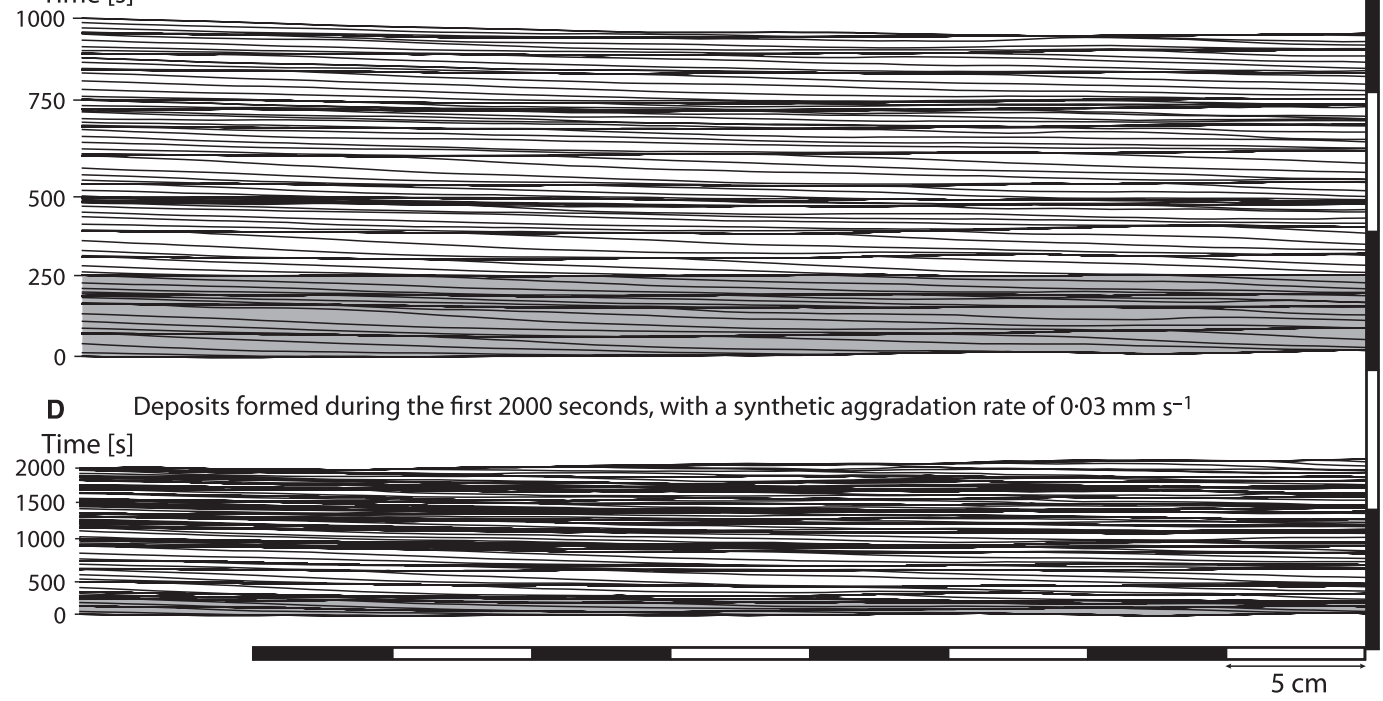

E Basal succession of (D) four times vertically exaggerated

Time $[\mathrm{s}]$

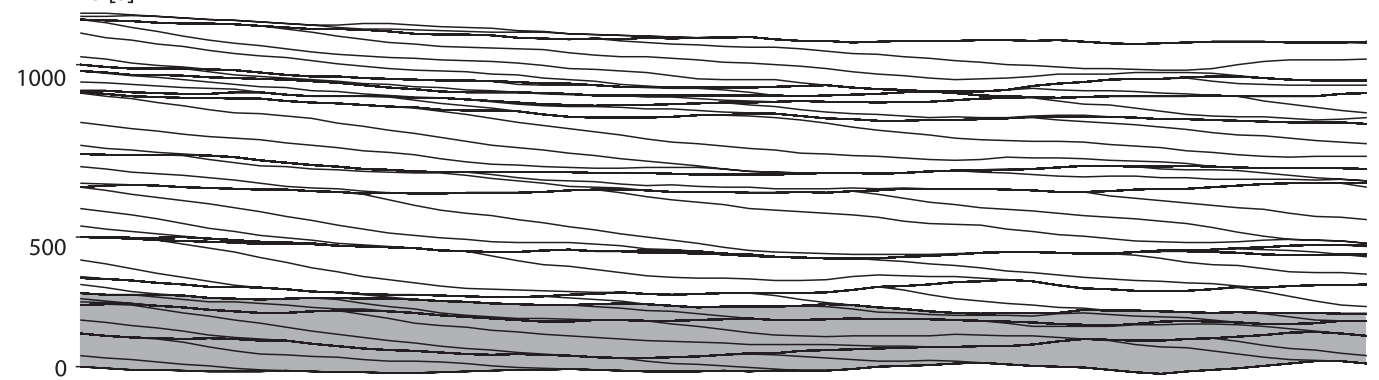

Fig. 5. Sedimentary structures of stable antidunes produced by synthetic aggradation. (A) Depth variations of sediment bed interface (continuous black) and free flow surface (dashed grey) plotted against time. (B) to (D) Sedimentary structures (no vertical exaggeration) developed by the flow shown in (A). Flow is from right to left. Run times indicated on the left correspond to the horizontal time axis in (A). Synthetic aggradation rates are 0.24 $\mathrm{mm} \mathrm{s}^{-1}$ in (B), $0.12 \mathrm{~mm} \mathrm{~s}^{-1}$ in (C) and $0.03 \mathrm{~mm} \mathrm{~s}^{-1}$ in (D). (E) Reproduction of the basal succession shown in (D) with a $4 \mathrm{x}$ vertical exaggeration. 
each set; and (iii) reduced relative variability in thickness between different lamina sets. The latter two characteristics naturally result from the lower impact of small variations in the depth of erosion, caused by fluctuations in antidune amplitude, on the overall geometry of thick sets. By contrast, lower aggradation rates imply: (i) laminae with approximately planar, subhorizontal geometry; (ii) greatly reduced thickness of lamina sets; and (iii) reduced and more variable lateral continuity of lamina sets, with preservation of lensoidal lamina sets in the extreme.

\section{Unstable antidunes}

\section{Morphodynamics}

At slightly higher flow energies $\left(F r_{90}=1.34\right)$, irregular trains of in-phase antidune waves turned into more regular, shorter trains, antidunes with breaking waves and subsequently non-breaking waves (Run 3). The process of wave breaking is shown in Figs $3 \mathrm{~B}$ and 6A (images $t_{1}-t_{4}$ ), and in Movie S2. As the upstream flank of the antidune wave became oversteepened, flow over the antidune crests started to slide back against the incoming flow, producing rollers or breaking waves that migrated upstream as positive surges (Fig. 6A; $t_{1}$ ). The positive surge was directly followed by a cloud of suspended sediment that extended almost over the entire water column $\left(t_{2}\right)$. As the surge migrated upstream into the adjacent antidune trough, its velocity and amplitude decreased $\left(t_{2}\right)$ and suspended sediment started to settle. The surge amplitude quickly abated while the propagation velocity of the surge decreased soon after the surge was flushed downstream as a negative surge $\left(t_{3}\right)$ while supercritical flow was re-established locally over the aggraded bed $\left(t_{4}\right)$. The new bed morphology was less undulating than in the previous phases, because the surge caused filling of the trough with sediment (as indicated by set boundaries in black). The process repeated with the formation of a new antidune and a new lamina set $\left(t_{5}-t_{7}\right)$. After several cycles of wave breaking at the head of the antidune trains, the process became less pronounced in the subsequent part of the train and seemed to be mainly driven by fluctuations in discharge caused by more violent breaking waves over the antidunes upstream. These wave breaking events at the head of the train were associated with deep scours, followed by a longer period ( $c a 100 \mathrm{~s}$ ) of bed aggradation and a general increase in Froude number $\left(t_{8}-t_{9}\right)$. This sequence of events was fol- lowed by a more stable, erosive flow (initial chute) at the tail of the train, which degraded the bed down to its previous level before starting a new train $\left(t_{10}\right)$. A panoramic view of the first $1200 \mathrm{~s}$ of Run 3 shows a vague repetitive pattern of trains of unstable antidunes (Fig. 6B). Flow domains undergoing aggradation were characterized by breaking surface waves, accompanied by suspension clouds and irregular peaks at the free surface, and alternated with flatter-bed domains dominated by erosive, supercritical flows (initial chutes). Wave trains formed quite regularly, but showed random patterns in amplitude and related erosion depth of the chute.

The Froude numbers plotted in Fig. 6C show a vague saw-tooth-like pattern, where steep declines to subcritical conditions (for example at ca $380 \mathrm{~s}$ ), associated with surges, were followed by gentle fluctuating rises into the supercritical regime (between $c a 400$ to $600 \mathrm{~s}$ ), up to the next decline to subcritical flow (at $c a 620$ s). Breaking waves superimposed on this signal were characterized by shorter wavelengths and smaller amplitude fluctuations. The spectrum of the bed interface showed a peak around 200 to 250 s associated with the antidune cycles (saw-tooth-like pattern). A much smaller barely significant peak in the bed interface graph is shown around $100 \mathrm{~s}$ (Fig. 6F), but there is no obvious process associated with it. The free-surface spectrum shows a similar peak around 200 to $250 \mathrm{~s}$ and a region of insignificant irregularities over a range of periods between 25 to $100 \mathrm{~s}$. Individual antidunes and breaking waves as seen on Fig. $6 \mathrm{~B}$ and $\mathrm{C}$ must contribute to this region. This insignificant range of irregularities is in contrast to the sharp significant peak of the stable antidunes (Fig. 4F). The differences between stable and unstable antidunes are expressed by higher $F_{90}$ and lower $F_{5}$ values for the unstable antidunes.

\section{Observed bedform architecture}

In contrast to the more continuous lamina sets formed by stable antidunes, deposits from unstable antidunes consisted of discontinuous lenticular beds with variable internal architecture, varying from backset to foreset (Figs $3 \mathrm{~B}$ and 6A; $t_{8}-t_{9}$ ). Lenticular structures formed as suspended sediment settled behind a migrating surge and filled the upstream trough. Depending on the maximum upstream position reached by the surge relative to the deepest point of the trough, sediment was deposited either mainly on the stoss side of the antidune, forming backsets $\left(t_{5} t_{7}\right)$, or it settled on the lee side of the next 
Run $3, Q=319 \cdot 8\left[\mathrm{~m}^{2} / \mathrm{h}\right]$

A
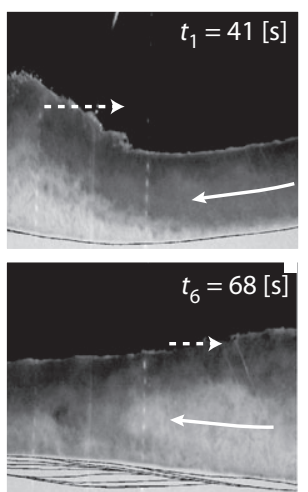
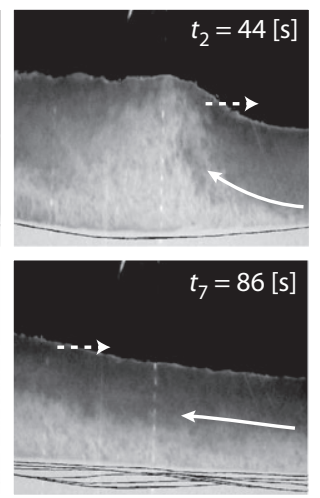
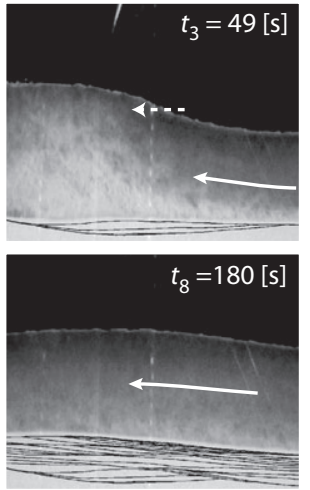
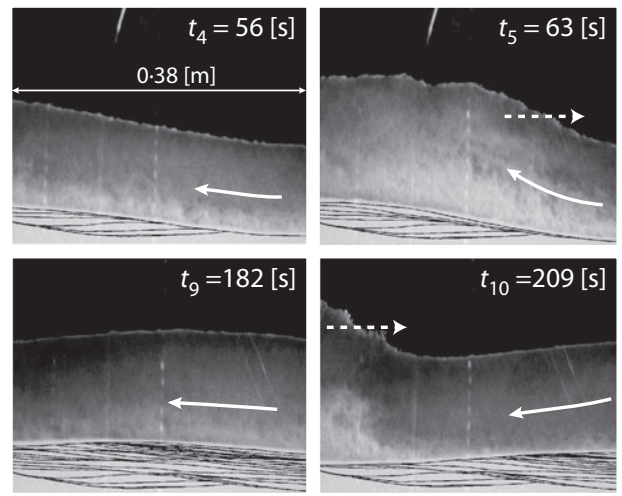
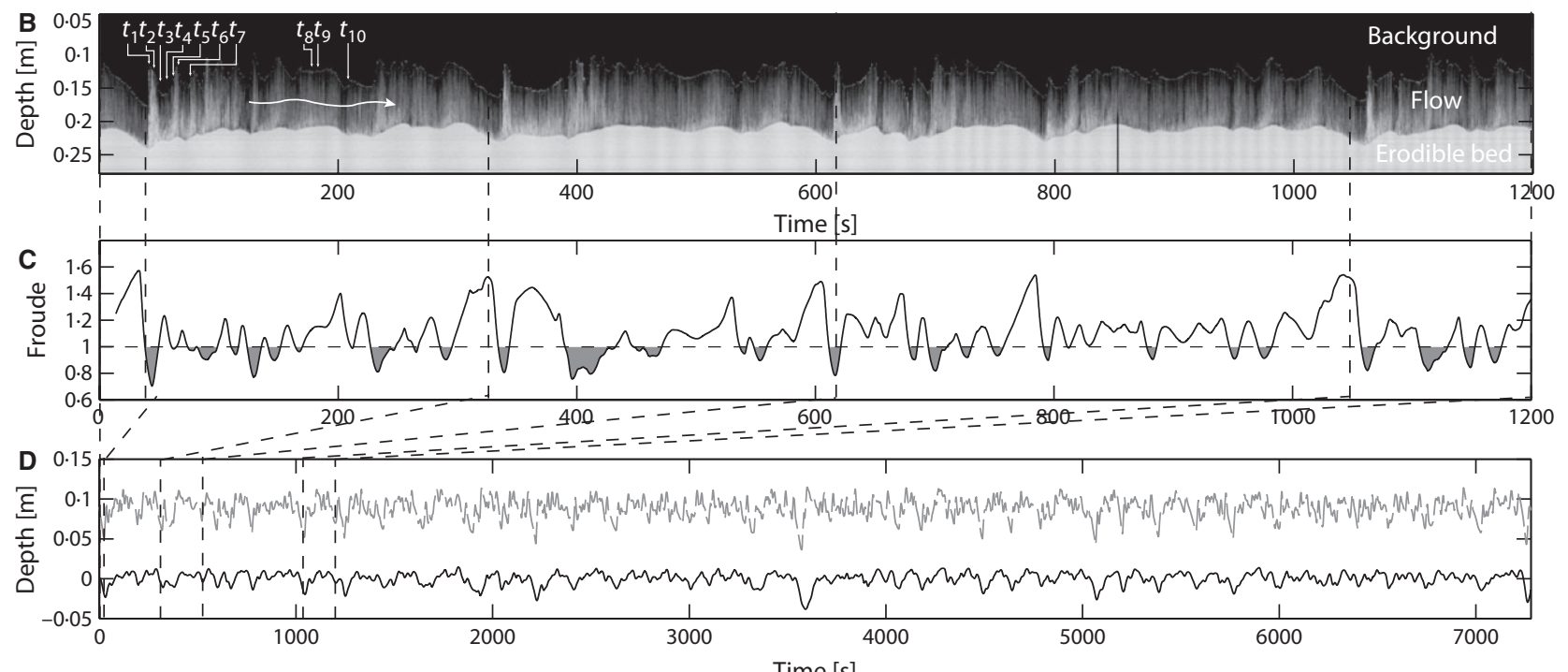

Time $[s]$
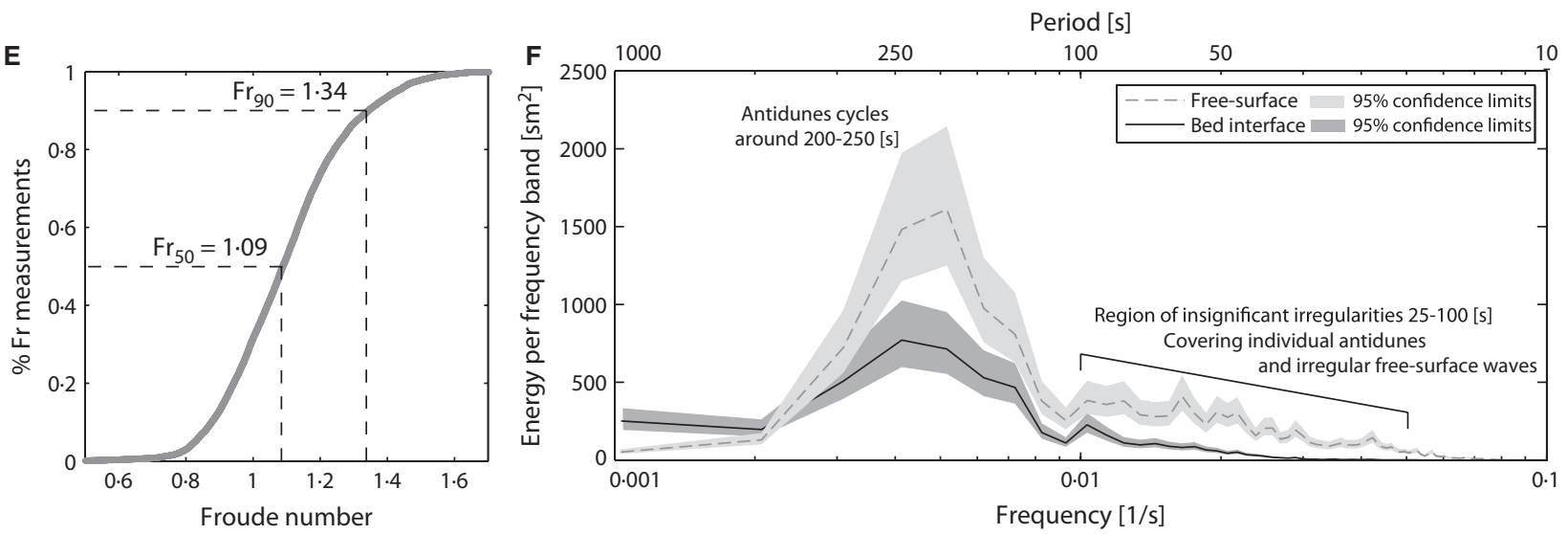

Fig. 6. Morphodynamics of unstable antidunes. Set up and methodology identical to Fig. 4. (A) Camera images. Arrows indicate flow direction (continuous) and surge migration direction (dashed). (B) Time series of unstable antidunes migrating upstream. (C) Plot of the Froude number (subcritical values are marked in grey). (D) Graph of the bed interface (continuous black) and free flow surface (dashed grey line) is comparable to (B), but for the full length of the run. (E) Distribution of Froude number over the entire flow. (F) Plot of the spectrum of both the sediment bed interface (continuous black) and the free flow surface (dashed grey).

antidune upstream forming low-angle foresets, while the surge migrated further upstream. If sediment settled around the middle portion of the trough, sets of curved symmetrical laminae were formed, conformable to the set boundary $\left(t_{1}-t_{4}\right)$. The process of wave breaking and the 
resulting positive surge were often associated with detachment of the high-velocity core of the incoming flow (jet) from the bed (as shown in oscillating jump; Fig. 2D). The sediment bed directly behind the surge was subject to strongly reduced traction, or even to reverse traction when a roller formed between the bed and the jet (Fig. 3B). Direct suspension fall-out within these regions of minor traction led to the accumulation of structureless deposits. Traction was regained gradually as the surge reduced in strength and migrated further upstream. Consequently, lenticular sets are structureless (massive) at the base, and grade vertically into more stratified deposits.

\section{Synthetic bedform architecture}

The obtained synthetic architecture of unstable antidune deposits is characterized by stacked lamina sets with undulating boundaries and internal laminae that join set boundaries tangentially (Fig. 7B to D). Compared with the deposits of stable antidunes, deposits of unstable antidunes show a larger variety of dip directions. It is possible to distinguish bundles of lamina sets corresponding to cycles of unstable antidunes (for example, 40 to $250 \mathrm{~s}$; Fig. 7, shown in grey); they consist of thicker, undular lamina sets showing variable dipping directions overlain by more regular, thinner lamina sets consisting of backset laminae. The more wavy basal sets represent surges triggered by waves breaking on the leading antidunes. Often the first breaking waves of an antidune train triggered the most violent surges that travel furthest upstream, and were most likely to form foreset laminae or laminae conformable to set boundaries, which therefore are most likely to be found at the base of sets. These violently breaking waves were then followed by more stable antidunes, which were reflected by more regular lamina sets composed of subhorizontal backsets. Images (Fig. 6A, $t_{s}-t_{g}$ ) show that stable antidunes follow the unstable antidunes described above. Deposits of stable antidunes were poorly preserved, because they are more likely to be eroded by the erosive higher Froude number flow (chute) at the end of the antidune train, even at high aggradation rates $\left(0.24 \mathrm{~mm} \mathrm{~s}^{-1}\right)$.

Successive timelines of bed development are plotted (4 s) in Fig. 7B to D. The wider separation of timelines, as seen in the wavy basal deposits, implies high aggradation rates due to en masse fall-out of sediment behind the surge in the absence of traction. This en masse fall-out makes the internal structures indicated by the timelines at the base of wavy layers less likely to be recognizable in the deposit. As surges slow down and start to be flushed downstream (negative surge), traction was restored (Fig. 3B), making the internal structure at the top of wavy sets more recognizable. Wavy basal laminae thus consisted of less pronounced laminae that tended to form foresets or boundary-conformable sets, grading vertically into more pronounced backsets.

Higher aggradation rates led to better preservation of the entire unstable antidune sequence, from the development of basal wavy sets to subhorizontal backset beds at the top. The convex bounding surfaces at the top of wavy sets were also better preserved at higher aggradation rates. Similar to stable antidune deposits, thicker sets had laminae dipping at higher angles and were characterized by greater lateral continuity than those formed at lower aggradation rates.

\section{Chutes-and-pools}

\section{Morphodynamics}

Runs that were characterized by higher $F_{90}$ in comparison with the runs described above, like Run 14 described here (see also Movie S3), show the formation of more pronounced trains of unstable antidunes and chutes (chutes-andpools). As described above, in the case of unstable antidunes, positive surges slowed down and were flushed back downstream (negative surges) over a restored flat bed, before starting a new cycle. By contrast, in the presence of chutesand-pools, positive surges slowed down and formed a hydraulic jump (temporarily stationary; Fig. 8A, $t_{1}-t_{2}$ ) until they were gradually replaced by a supercritical flow initiating a new surge $\left(t_{3}-t_{4}\right)$. A positive relief was locally built up by massive settling of suspended sediment downstream of the hydraulic jump $\left(t_{1}-t_{2}\right)$. Such rapid aggradation, in turn, further limited the flow depth and forced a return from a hydraulic jump to supercritical-flow conditions $\left(t_{2}\right)$. The renewed supercritical flow started to break again over a wavy bed to form a new surge, thus repeating the process $\left(t_{3}\right)$.

Although the process transition between unstable antidunes and chutes-and-pools was gradual, some clear distinctions can be made. Firstly, as mentioned above, surges were no longer flushed downstream, probably due to the rapid build-up of localized sediment accumulation directly downstream of the surge $\left(t_{1}-t_{2}\right)$. Secondly, the undulating relief, formed by en masse sediment fall-out directly behind surges or hydraulic 

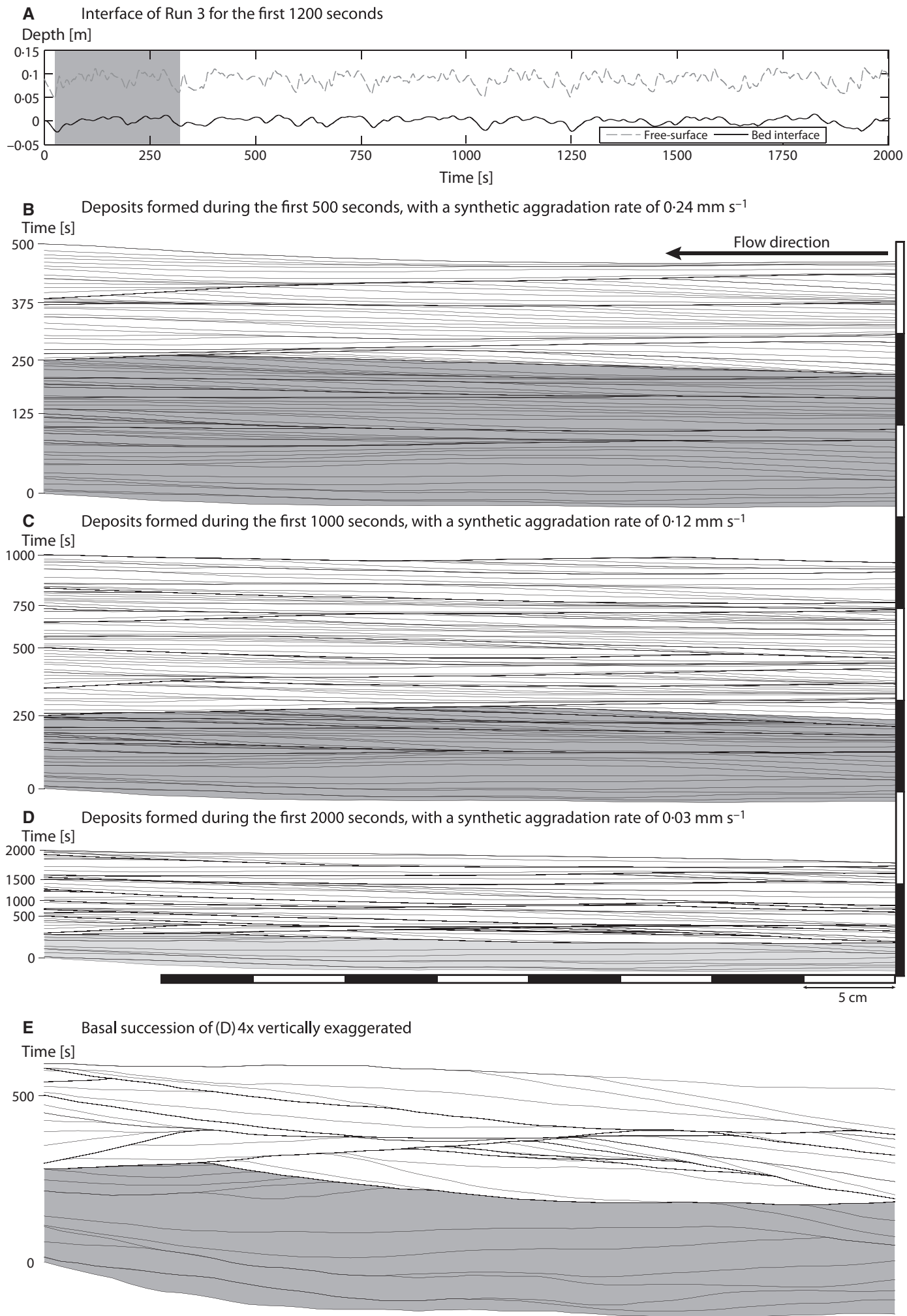

Fig. 7. Sedimentary structures of unstable antidunes produced by synthetic aggradation. (A) Depth variations of sediment bed interface (continuous black) and free surface (dashed grey) plotted against time intervals of $4 \mathrm{~s}$. (B) to (D) Sedimentary structures developed by the flow shown in (A). Flow is from right to left. Run times indicated on the left correspond to the horizontal time axis in (A). Synthetic aggradation rates are $0.24 \mathrm{~mm} \mathrm{~s}^{-1}$ in (B), $0.12 \mathrm{~mm} \mathrm{~s}^{-1}$ in (C) and $0.03 \mathrm{~mm} \mathrm{~s}^{-1}$ in (D). (E) Reproduction of the basal succession shown in (D) with a $4 \mathrm{x}$ vertical exaggeration.

(C) 2013 The Authors. Journal compilation (C) 2013 International Association of Sedimentologists, Sedimentology, 61, 712-748 
Run $14, Q=302 \cdot 3\left[\mathrm{~m}^{2} / \mathrm{h}\right]$

A
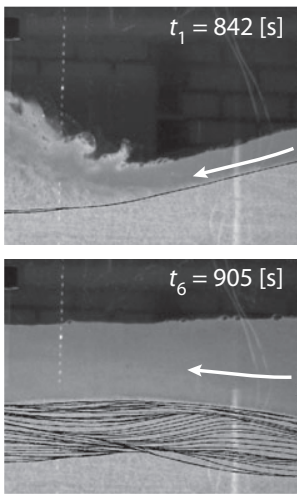
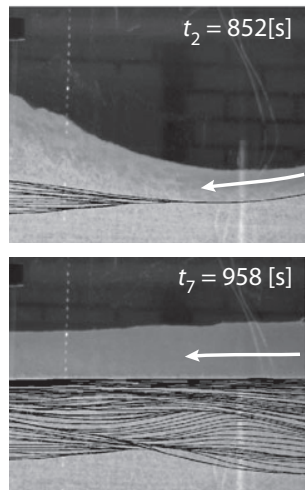
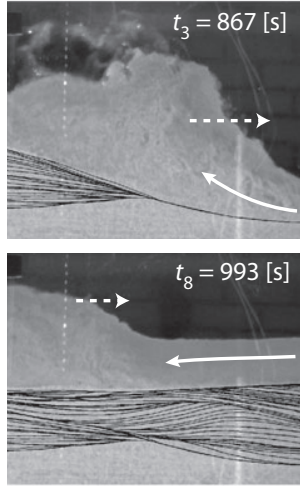
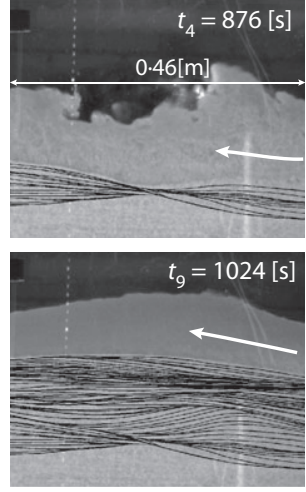
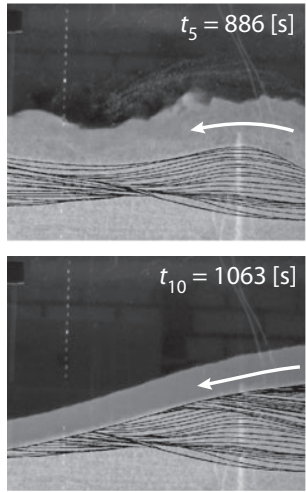
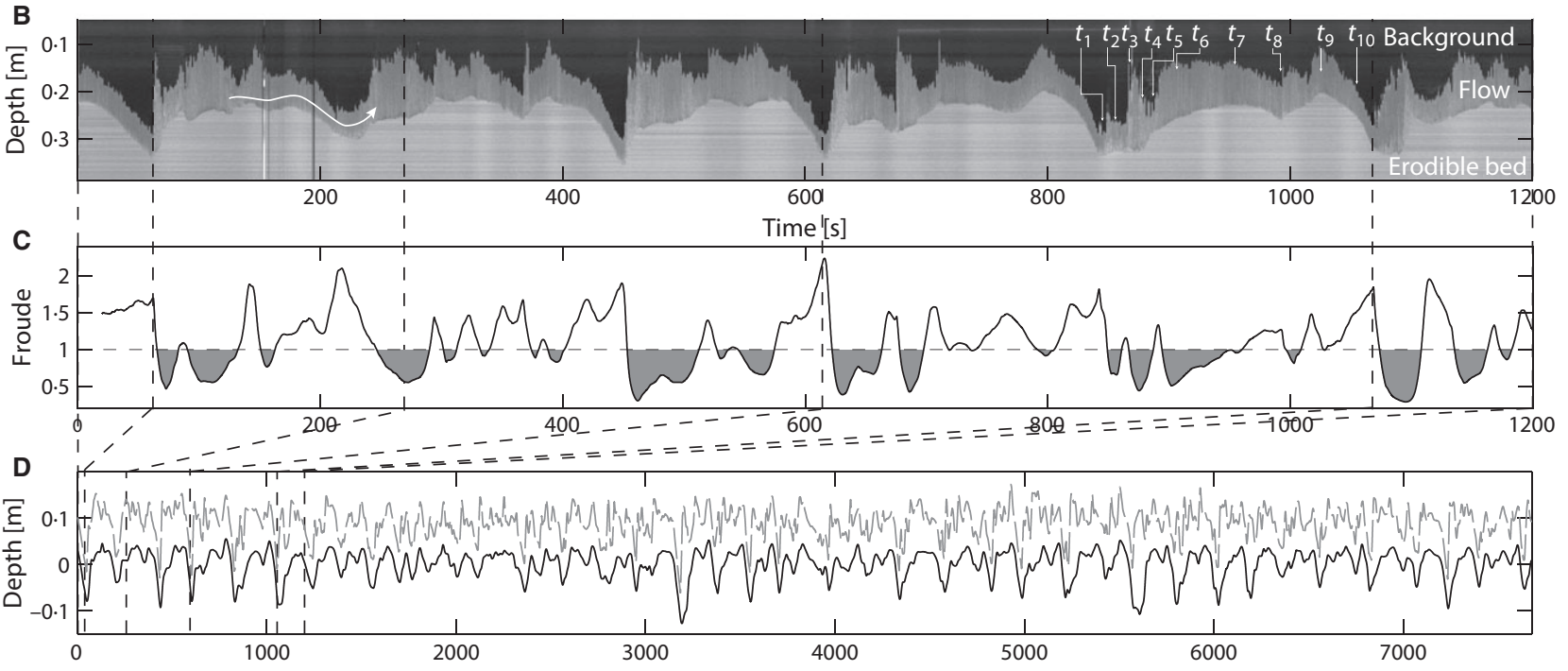

E

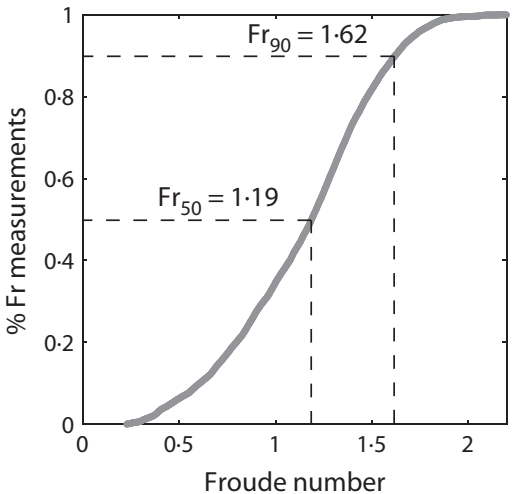

Period $[s]$

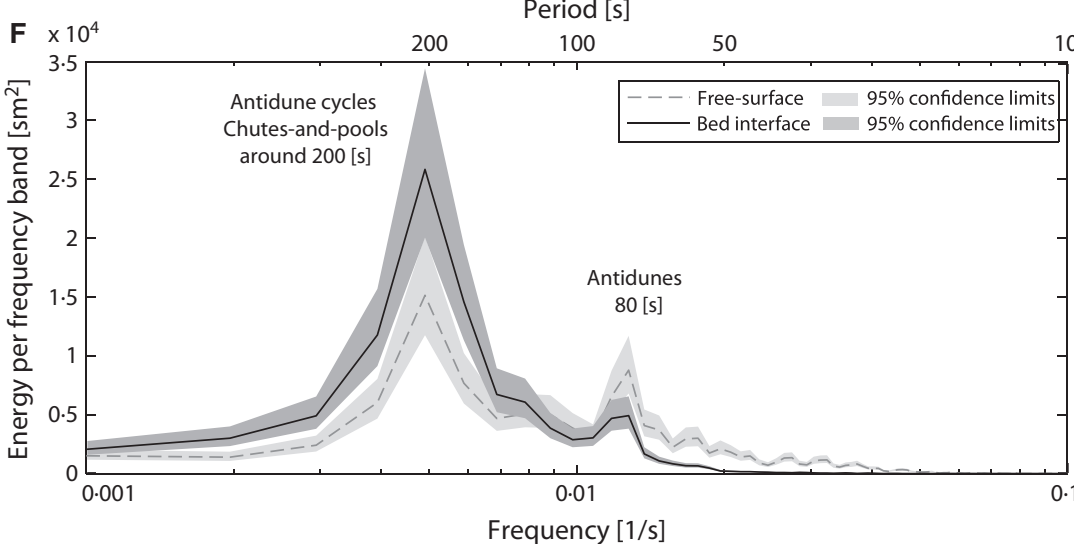

Fig. 8. Morphodynamics of chutes-and-pools. Set up and methodology identical to Fig. 4. (A) Camera images; arrows indicate flow direction (continuous) and surge migration direction (dashed). (B) Time series of migrating chutes-and-pools. (C) Plot of the Froude number. (D) Graph of the bed interface (continuous black) and free surface (dashed grey) is comparable to (B), but for the full length of the run. (E) Distribution of Froude number over the entire flow. (F) Plot of the spectrum of both the sediment bed interface (continuous black) and the free flow surface (dashed grey).

jumps, replaced the leading unstable antidunes which were strongly associated with free-surface waves.
Compared with unstable antidunes (Fig. 6B), chutes-and-pools (Fig. 8B) were dominated by longer cycles (chutes-and-pools) over shorter 
wavelength cycles (antidunes). Strongly erosive chutes were directly followed by strong aggradation downstream of hydraulic jumps or surges. Between these chutes-and-pools, slow aggradation occurred below antidunes and weaker surges. The saw-tooth-like signal in Froude number (Fig. 8C) was more pronounced than in the two former antidune cases (Figs 4 to 6C) and can be subdivided into an upstream, mainly subcritical part immediately downstream of the decline in Froude number related to the surge or jump, followed further downstream by an almost uninterrupted supercritical part, although superimposed smaller fluctuations remain numerous. Comparing the morphological evolution of sedimentary interfaces over full runs of unstable antidunes and chutes-and-pools showed a similar periodicity ( $c a 200 \mathrm{~s}$ ), but the antidune amplitudes (ca $0.02 \mathrm{~m}$ ) became smaller relative to the chute-and-pool amplitudes ( $c a$ $0 \cdot 1 \mathrm{~m}$; Fig. 8).

Due to the hydraulic jumps and subsequent subcritical flow regions, the $F_{50}$ here $\left(F r_{50}=1.19\right)$ was not much higher than for unstable antidunes (1.09), while the $F_{90}$ increased from 1.34 to 1.62 (Fig. 8E). The general shape in the spectral plots (Fig. 8F) resembled those found for unstable antidunes for the long wavelength cycles (around 200 seconds), but here the shorter period peak (around 80 seconds) was more pronounced and focused in comparison with the unstable antidune spectrum.

\section{Observed bedform architecture}

Deposits formed by chutes-and-pools (Figs 3C and $8 \mathrm{~A}$ ) represented a continuation of the trend seen at the transition from stable antidunes to unstable antidunes. The wavy geometry of set boundaries was enhanced and lenticular sets dominated the sequence, with the thicker lamina sets showing more variability in the dip of laminae. The variability is ascribed to the stepwise migration of the surge (Fig. 8A). As the surge moved upstream $\left(t_{3}\right)$, its velocity decreased and instead of being flushed downstream the surge converted into a stationary hydraulic jump $\left(t_{1}, t_{4-5}\right)$. Just downstream of the hydraulic jump $\left(t_{1-2}, t_{4-5}\right)$, thick lenticular beds were formed, which were structureless in their basal parts, having formed under conditions of rapid deposition from suspension and the absence of traction $\left(t_{1}, t_{4}\right)$. As local aggradation forced the flow to reaccelerate over the lens $\left(t_{2}\right.$, $t_{5}$ ), the top of the lenticular unit was reworked into foreset laminae $\left(t_{5}\right)$ by tractive sediment transport. As the leading edge of the chute-andpool migrated further upstream, the interstratified layer of lenticular sets was draped by a swaley-like stratified layer formed by traction in an accelerating flow. At the crest of the chute-andpool, the flow was supercritical and only slightly depositional, leaving behind regular antidune backsets $\left(t_{g}\right)$. Eventually, all sediment was reworked by the chute $\left(t_{10}\right)$.

\section{Synthetic bedform architecture}

The overall structure, when developed under high aggradation rates, closely resembles hummocky cross-stratification. However, synthetic aggradation sequences (Fig. 9B to D) suggested that preservation of an entire chute-and-pool structure in the rock record required very high aggradation rates. Basal wavy sets were dominant and the wide spacing between timelines indicates that most of the preserved sediment was deposited by rapid particle deposition, resulting in structureless, lenticular sand lenses. The thicker undulatory sets again showed a variety of dip directions, whereas thinner ones were mainly represented by backsets. Dip directions grade vertically from backsets (related to the surge stage) to boundary-conform (hydraulic-jump stage), ending in reworked foresets (supercritical flow stage), thereby showing an opposite trend to that observed under unstable antidunes (foresetboundary conform-backset).

With increasing aggradation rate, greater portions of the structural sequence were preserved, producing thin, swaley-like sets between lenticular units. The preservation potential of the convex tops was severely limited at low aggradation rates. At the lowest aggradation rates adopted here, many lenticular sets were replaced by stacked internal scours, which prevented the recognition of the hummocky-like chute-and-pool sequences. At higher aggradation rates $(0.12$ and $\left.0.24 \mathrm{~mm} \mathrm{~s}^{-1}\right)$, chute-and-pool sequences $(t=40$ to $220 \mathrm{~s}$, shown in grey) can be recognizable by more continuous, erosional surfaces at the scale of antidune dimensions. It is worth noting that the lowest aggradation rate also led to the most massive (structureless) character to the deposits, which can be ascribed to the preferential preservation of the basal wavy sets.

\section{Cyclic steps}

\section{Morphodynamics}

From chute-and-pool conditions, a slight increase in flow energy will trigger the formation 
A Interface of Run14 for the first 1200 seconds

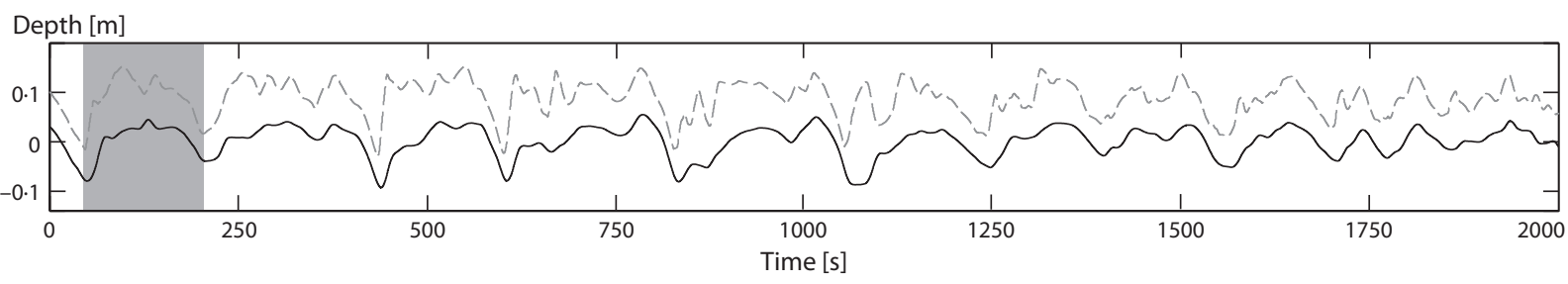

B Deposits formed during the first 500 seconds, with a synthetic aggradation rate of $0.24 \mathrm{~mm} \mathrm{~s}^{-1}$ Time $[\mathrm{s}]$ 500
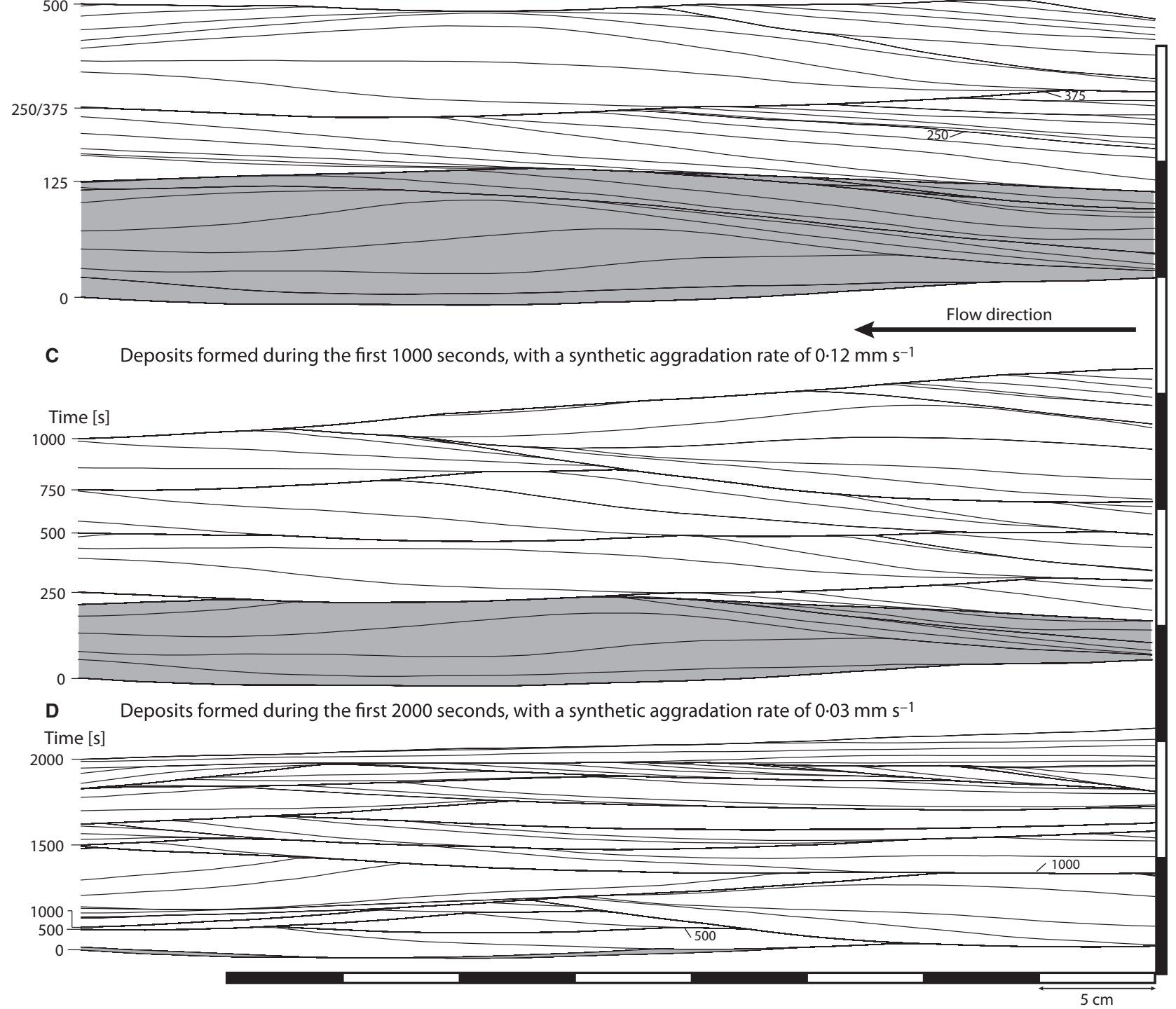

Fig. 9. Sedimentary structures of chutes-and-pools produced by synthetic aggradation. (A) Depth variations of sediment bed interface (continuous black) and free flow surface (dashed grey) plotted against time. (B) to (D) Sedimentary structures developed by the flow shown in (A). Flow is from right to left. Run times indicated on the left correspond to the horizontal time axis in (A). Synthetic aggradation rates are $0.24 \mathrm{~mm} \mathrm{~s}^{-1}$ in (B), $0.12 \mathrm{~mm} \mathrm{~s}$ in (C) and $0.03 \mathrm{~mm} \mathrm{~s}^{-1}$ in (D).

of cyclic steps, as observed in Run 9 (see also Movie S4). The flow plunged over lee sides that steeply dipped downstream, passed through a hydraulic jump in the troughs, and reaccelerated over stoss sides that gently dipped upstream (Fig. 3D). Because sediment was deposited 
mainly on the stoss sides, internal structures consisted of backset laminae onlapping onto the inclined lee sides. Prevalent erosion over the lee side and in the trough forced an upstream migration of these bedforms. These cyclic step runs show a further increase in $F_{90}$ values, leading to different hydraulic jump dynamics and thereby to the transformation from chutesand-pools to cyclic steps. Hydraulic jumps in chutes-and-pools generally migrated upstream in a stepwise manner due to the superimposed unstable antidunes downstream of the chute, whereas in cyclic steps hydraulic jumps migrated at more or less stable rates and remained fixed in their position relative to the associated bedform (Fig. 10B; $t_{1}, t_{6}, t_{10}, t_{14}$ ). In the wake of the hydraulic jump, particles settled rapidly from suspension, producing massive deposits just as in chutes-and-pools; however, the hydraulic jump seemed no longer directly influenced by these deposits, because it migrated continuously upstream and away from the point of greatest deposition. This process is shown in Fig. 10A, where a hydraulic jump migrated upstream $\left(t_{1}\right)$ directly followed by a suspension cloud $\left(t_{2}\right)$. The deposits that followed the hydraulic jump aggraded progressively and forced the subcritical flow to accelerate $\left(t_{4}-t_{5}\right)$. As the flow accelerated, it became erosive again and eroded the chute $\left(t_{5}\right)$ leading to a successive hydraulic jump, where the process was repeated $\left(t_{6}-t_{10}\right)$. The overall morphology of the cyclic step (Fig. 10B) shows that, although the process is fairly regular, the position of the hydraulic jump between individual bedforms varied. At some cyclic steps, the hydraulic jump was located on to the lee side (submerged hydraulic jump; Fig: 2I) (80, 400 and $500 \mathrm{~s}$ ), whereas other cyclic steps presented hydraulic jumps in the deepest part of the trough (100, 300, 550, 650, 700 and $800 \mathrm{~s})$.

Froude numbers showed a much more regular saw-tooth-like pattern than measured for unstable antidunes and chutes-and-pools. Observed fluctuations were very small, because irregular surges have been replaced by steadily migrating stable hydraulic jumps with long periods of subcritical flow downstream of the jump, which led to reduced median Froude number values $\left(F r_{50}=0.95\right)$. However, $F r_{90}(2 \cdot 18)$ was still higher than in chutes-and-pools $\left(F r_{90}=1 \cdot 62\right)$. The spectral plot (Fig. 10F) shows a dominant period of $\mathrm{Ca} 80$ to $120 \mathrm{~s}$, which corresponds well to the average cyclic step period. The amplitude of cyclic steps varied over time
(Fig. 10B and D). Considering the two cyclic steps around $c a 800 \mathrm{~s}$ (Fig. 10B), it seems that high Froude numbers along the chute of cyclic step at $t=800 \mathrm{~s}$ reduced the wavelengths of the cyclic step immediately downstream, because high Froude numbers were conjugated by the hydraulic jump to lower subcritical Froude numbers.

\section{Observed bedform architecture}

Cyclic step architecture consisted of backset laminae with a massive basal part, formed from direct particle fall-out downstream of the hydraulic jumps, and graded vertically into more stratified backsets $\left(t_{4}-t_{5}, t_{8}-t_{9}\right)$. Lamina thickness and dip were proportional to sedimentation rate. Some of the toes of the backsets consisted of boundary-conform sets. This geometric variability resulted from the distance between the deepest part of the trough and the position of the hydraulic jump. If the deepest part of the trough was close to the hydraulic jump (Fig. 10A; $t_{1}, t_{6}$ ), as was the case for flushed and normal jumps (Fig. 2G and H), backset laminae were formed $\left(t_{3}\right.$ and $t_{8}$ ). In the case of submerged (Fig. 2I) hydraulic jumps $\left(t_{10}, t_{14}\right)$, the distance between the jump and the deepest part of the trough was much larger, which caused sediments to drape the trough and to form laminae conformable to the lower boundary $\left(\mathrm{t}_{12}-t_{13}\right)$. The position of the hydraulic jump relative the geometry of the cyclic step was controlled by flow thickness, by the height of the stoss side pushing the hydraulic jump upstream, and by the kinetic energy of the flow along the bedform lee side pushing the hydraulic jump downstream. Cyclic steps with low amplitudes generally had hydraulic jumps close to the point of maximum scour, while increasing bedform amplitudes tended to submerge the hydraulic jump on the lee side, producing more draping geometries and boundary-conform laminae.

\section{Synthetic bedform architecture}

The deposits of cyclic steps consisted of very elongated, generally concave lenses that truncated each other at low angles (see also vertically exaggerated Figs 3D and 11). Synthetic aggradation sequences showed that structures were generally continuous, but interrupted by nested, elongate internal scours of much larger scale than shown on the images used to construct the sequences (Fig. 11). The erosional basal surfaces traced variations in incision depth of the trough through time. Erosional surfaces 
Run $9, Q=257.5\left[\mathrm{~m}^{2} / \mathrm{h}\right]$
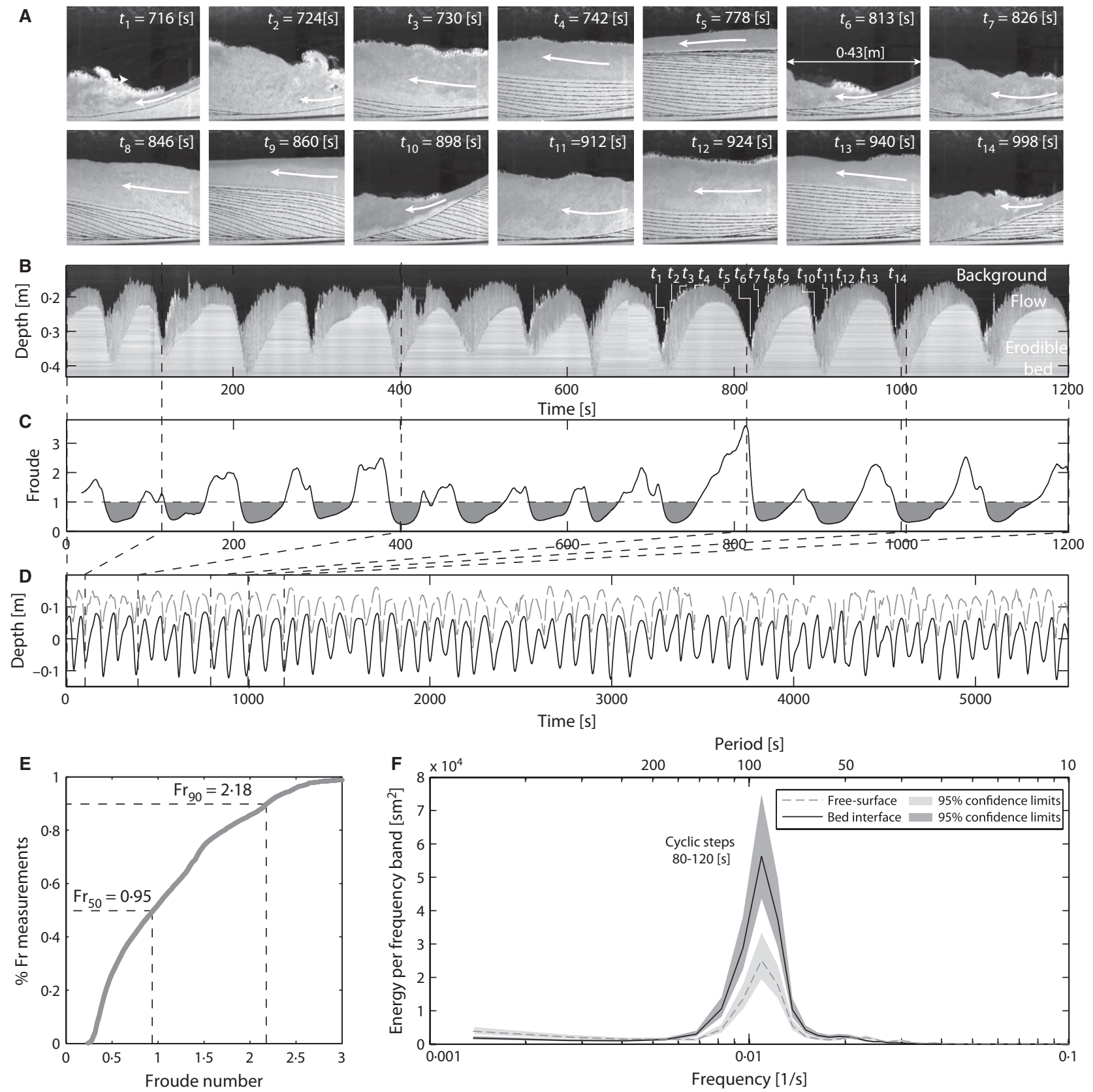

Fig. 10. Morphodynamics of cyclic steps; set up and methodology identical to Fig. 4. (A) Camera images; arrows indicate flow direction. (B) Time series of cyclic steps migrating upstream. (C) Plot of the Froude number. (D) Graph of the bed interface (continuous black) and free flow surface (dashed grey) is comparable to (B), but for the full length of the run. (E) Distribution of Froude number over the entire flow. (F) Plot of the spectrum of both the sediment bed interface (continuous black) and the free flow surface (dashed grey).

commonly started upstream with relatively steep angles $\left(\mathrm{t}_{12}\right)$, and extended downstream with a more gentle dip upcurrent, forming a curved, spoon-shaped geometry which indicates that incision depths changed through time as bedforms migrated.
Timelines in Fig. 11B to D have been traced at closer intervals ( $2 \mathrm{~s}$ ) than in previous examples $(4 \mathrm{~s})$ in order to ensure the stacking of sufficient timelines to produce a clear structure. Notwithstanding these shorter time intervals, the vertical spacing of these lines is large, show- 
A Free surface and bed interface of Run 9 for $400-2400$ seconds

Depth [m]

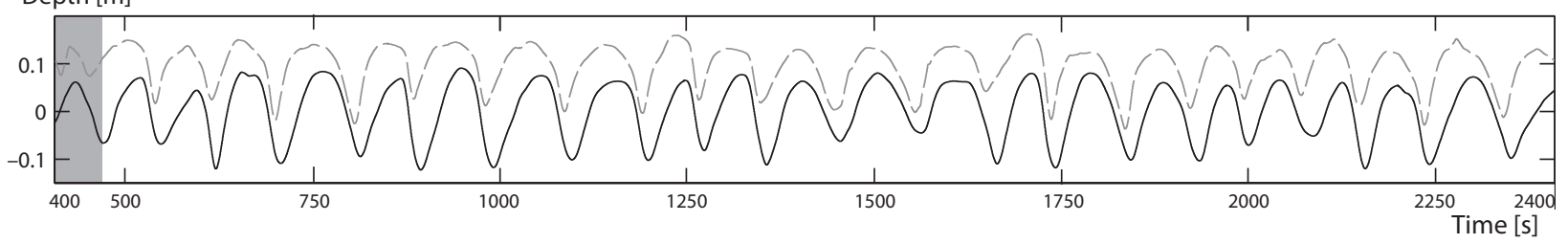

B Deposits formed during the first 400-900 seconds, with a synthetic aggradation rate of $0.24 \mathrm{~mm} \mathrm{~s}^{-1}$

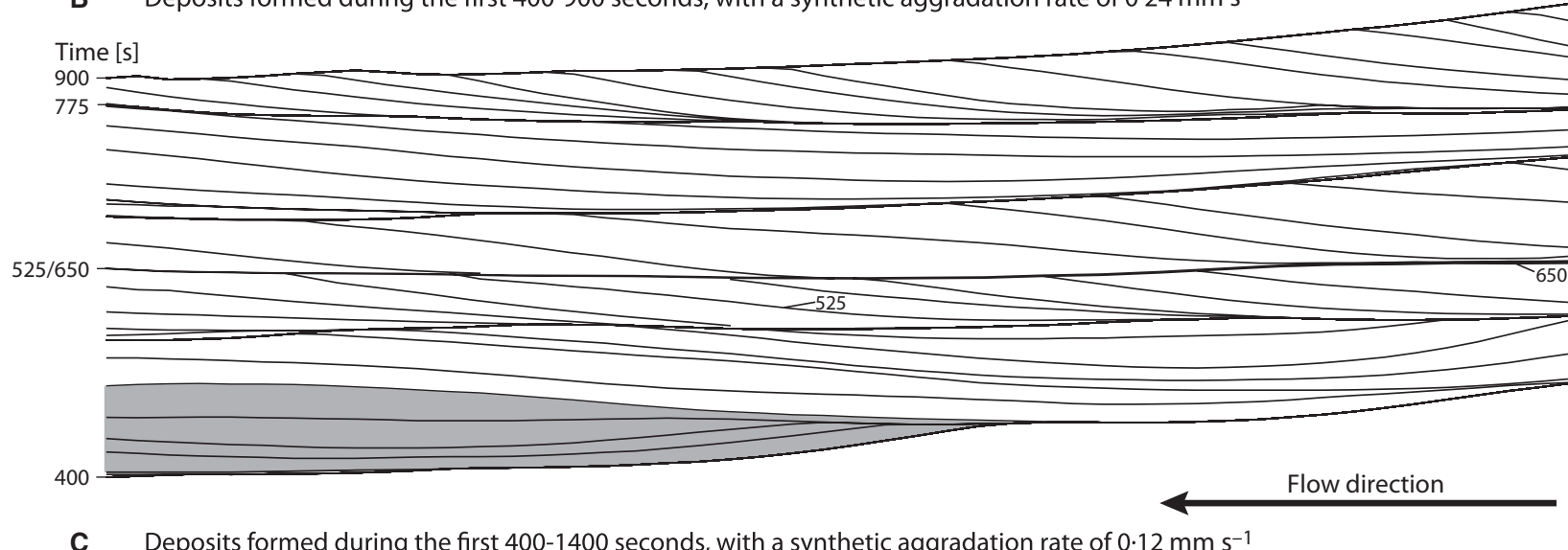

C Deposits formed during the first 400-1400 seconds, with a synthetic aggradation rate of $0.12 \mathrm{~mm} \mathrm{~s}^{-1}$

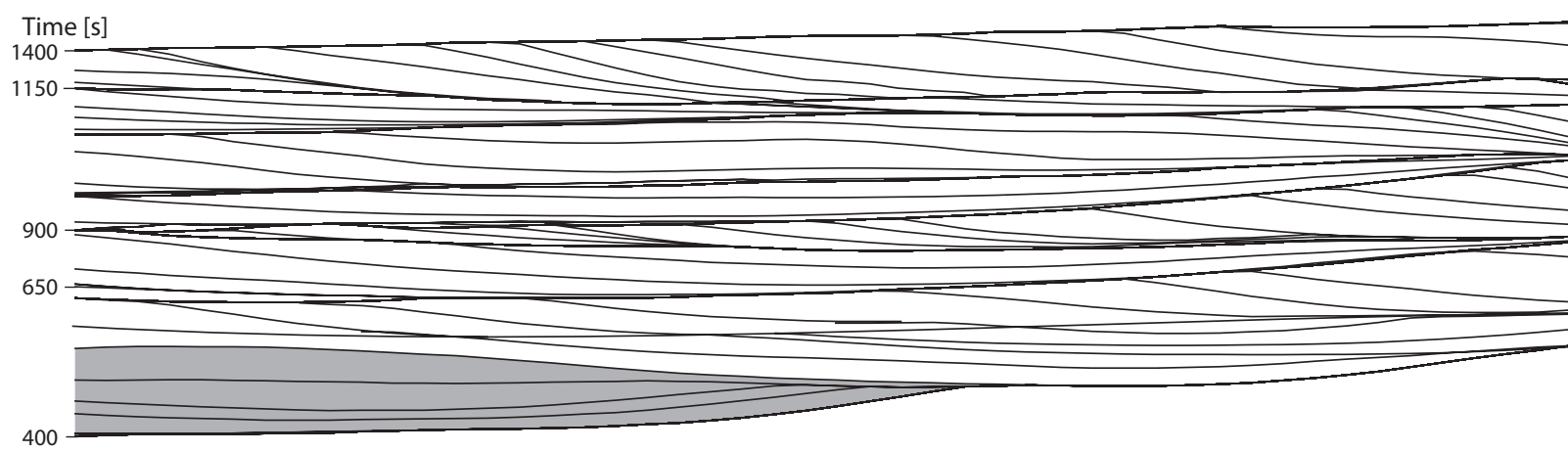

D Deposits formed during the first 400-2400 seconds, with a synthetic aggradation rate of $0.03 \mathrm{~mm} \mathrm{~s}^{-1}$

Time $[\mathrm{s}]$

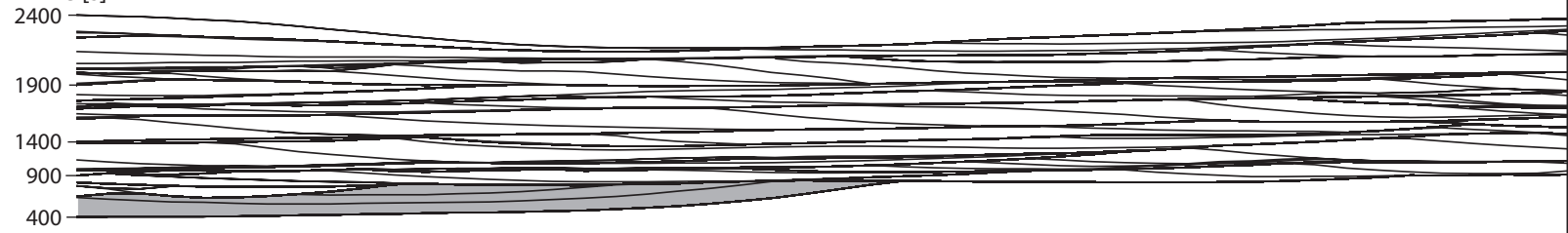

400
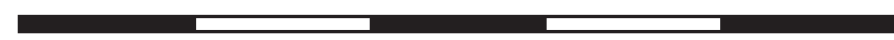

$5 \mathrm{~cm}$

Fig. 11. Sedimentary structures of cyclic steps produced by synthetic aggradation. (A) Depth variations of sediment bed interface (continuous black) and free flow surface (dashed grey) plotted against time. (B) to (D) Sedimentary structures developed by the flow shown in (A). Flow is from right to left. Run times indicated on the left correspond to the horizontal time axis in (A). Synthetic aggradation rates are $0.24 \mathrm{~mm} \mathrm{~s}^{-1}$ in (B), $0.12 \mathrm{~mm} \mathrm{~s}$ in (C) and $0.03 \mathrm{~mm} \mathrm{~s}^{-1}$ in (D).

ing that the lamina sets formed under even higher local deposition rates than in previous bedforms. This high aggradation rate made traction stratification even more uncommon.
The role of aggradation rate was less pronounced in cyclic step bedforms in comparison with the other bedforms. Thinner units formed in response to low aggradation rates and were 
more elongate than those formed at high aggradation rates, which made them difficult to distinguish from other bedforms. Dip angles were also reduced at low aggradation rates, because of the tangential toes of laminae. Furthermore, high aggradation rates were more likely to preserve backsets on top of the structureless basal layer.

\section{DISCUSSION}

\section{Stability diagram}

Bedform stability diagrams are a powerful tool, linking sedimentary structures to flow parameters (Simons \& Richardson, 1966; Vanoni, 1974; Van Rijn, 1984a,b; Southard \& Boguchwal, 1990; Van den Berg \& Van Gelder, 1993), and can now be extended further into the supercritical-flow regime by plotting the data presented here as well as data from the literature. The stability diagrams of Southard \& Boguchwal (1990) and Van den Berg \& Van Gelder (1993, 1998) are used as a basis.

Simple inclusion of supercritical-bedform data into one of the existing bedform diagrams is not straightforward due to strongly fluctuating flow conditions over the bedforms. For bedforms in the subcritical regime, depth and time averaged flow properties, such as flow velocity or Froude number, can be plotted against grain size. In the supercritical regime, however, strong fluctuations in flow velocity decrease median values while the overall flow energy is increased, thereby preventing direct plotting of median time-average values. To overcome this problem, the $90^{\text {th }}$ percentile values (for example, $U_{90}$ ) were used, since these values increase with flow energy and are similar to the median values $\left(U_{50}\right)$ for subcritical flows, where bedforms can be assumed to be small in comparison to the flow depth.

The experimental data were plotted in the diagram of Southard \& Boguchwal (Fig. 12A; black markers), using their $0 \cdot 06$ to $0 \cdot 1 \mathrm{~m}$ water depth $\left(10^{\circ} \mathrm{C}\right)$ diagram. Previously published bedform data (Table 2) formed in supercritical flows with depths between $0.05 \mathrm{~m}$ and $0.15 \mathrm{~m}$ were also included (Fig. 12A; grey markers). Published data, however, generally do not indicate values of $U_{90}$. To enable plotting of this data, averaged velocities $\left(U_{50}\right)$ were converted to $U_{90}$ by using ratios $U_{50} / U_{90}$ derived from the experiments presented here (Fig. 13A). Critical Vedernikov values $(V e=1)$ for $0.08 \mathrm{~m}$ deep flows are indicated by a grey band in Fig. 12. This band indicates the spread of values depending on the choice of $x$ between $1 / 2$ and 2/3.

The experimental data were also plotted in the stability diagram of Van den Berg \& Van Gelder (1993), which uses the mobility parameter and a dimensionless grain size on the axes to plot a wider range of flow depths within a single diagram. The original diagram of Van den Berg \& Van Gelder (1993) is only valid for subcritical flows. However, constant Froude number values (0.84 and 1), for a fixed flow depth, here set to $0.08 \mathrm{~m}$, can be included (Fig. 12B; Van den Berg \& Van Gelder, 1998). At field scale, the Froude critical line will shift upward leaving a larger part of the diagram open for subcritical conditions, because larger values of velocity and mobility parameters are needed to achieve supercritical flows at greater flow depths. An additional indication for unity Vedernikov numbers is added in the diagram of Van den Berg and Van Gelder (Fig. 12B) to mark the area that separates the supercritical-flow region into stable $(F r>1, V e<1)$ and unstable $(F r>1, V e>1)$ domains. If $\mathrm{D}_{90}$ grain size was not provided for the data extracted from the literature, $D_{90}=3 D_{50}$ was assumed, while the temperature was set at $20^{\circ} \mathrm{C}$ by fixing water viscosity on $v=1.00510^{-6}$.

Both stability diagrams (Fig. 12) show the transition from upper flow-regime plane bed, through antidunes and chutes-and-pools, to cyclic steps as flow energy, mobility parameter or depth-average velocity, increases. The stability diagram based on the mobility parameter indicates more consistent boundaries between different bedforms than the stability diagram based on flow velocity, probably as a result of the nondimensional parameters. The onset of the stability fields for upper-stage plane bed is distinct in both diagrams (Fig. 12) for Froude numbers between 0.84 and 1 , keeping in mind the variability in flow depths, followed by antidunes as flows become supercritical. For fine and medium sand, the transition to unstable bedforms (chutes-and-pools and cyclic steps) is reasonably well-defined by Vedernikov numbers around unity. For coarse sand, the transition to unstable flows starts to deviate from $V e=1$ and occurs only at higher flow energy. In fine sand, a slight increase in flow energy transforms antidunes almost directly to cyclic steps, while for the coarser grain sizes this transition is more gradual, thus expanding the transitional phase of chutes-and-pools and unstable antidunes. The 
Fig. 12. Extended bedform stability diagrams of: (A) the diagram of Southard \& Boguchwal (1990; for a 0.06 to $0.1 \mathrm{~m}$ water depth and water temperature of $10^{\circ} \mathrm{C}$ ); and (B) Van den Berg \& Van Gelder (1998). Data from this study are plotted in black. Converted literature data are added in grey (see Table 2 for references). Lines added in this study are water depth dependent and only valid for water depth of $0.08 \mathrm{~m}$. Symbols correspond to the different bedforms as shown in the middle of the figure.
Particle diameter $\mathrm{d}_{50}[\mathrm{~mm}]$
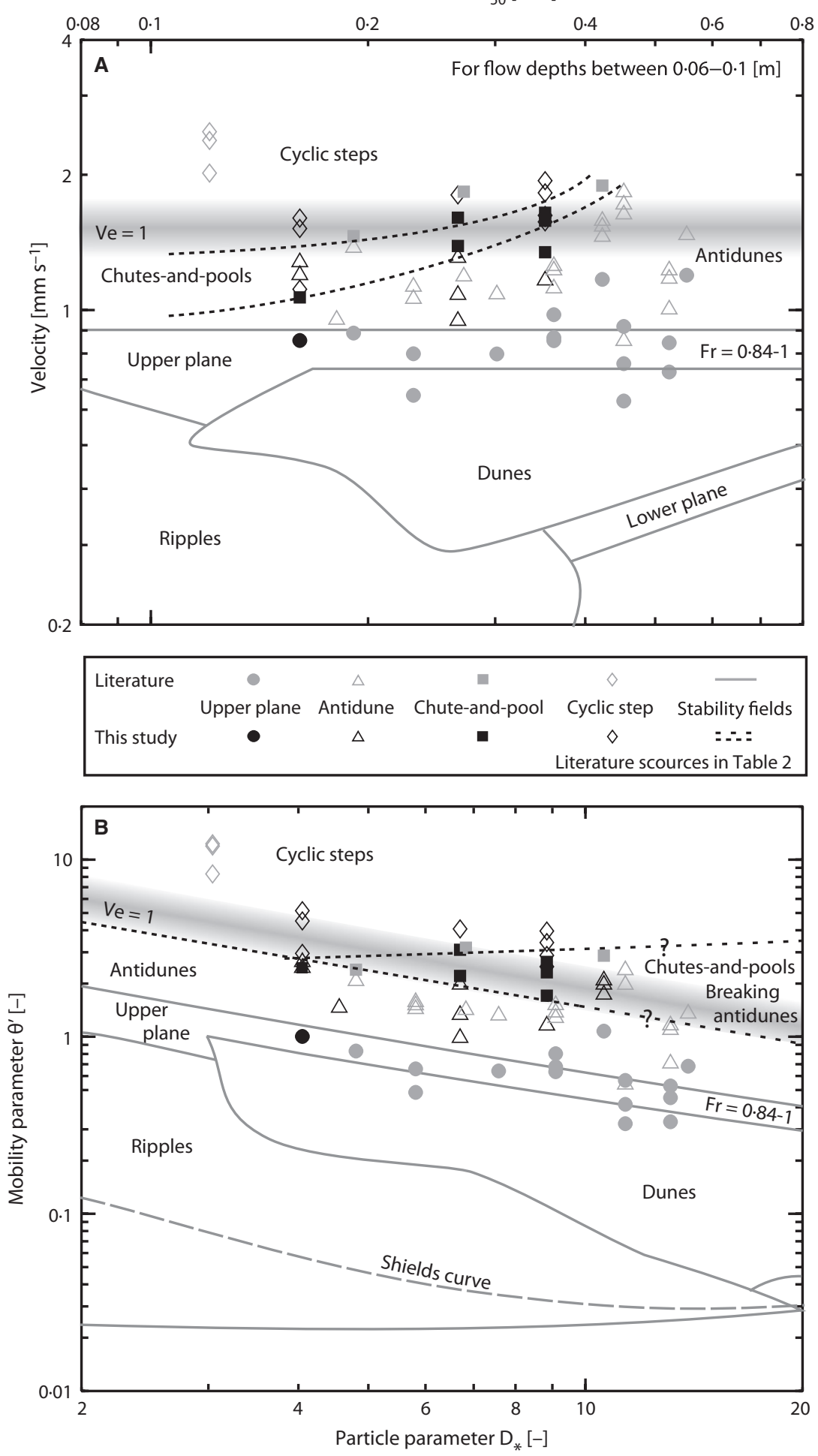

final transition from chutes-and-pools to antidunes occurs around mobility parameters of $c a$ 3. To gain more insight into the transition, the mobility parameter was plotted against Froude numbers in Fig. 13C. Here, upper flat bed and antidunes differ from chutes-and-pools and cyclic steps in their relation to the Froude number. The formation of flat beds and antidunes is well-correlated with Froude numbers, indicating a driving mechanism mainly related to fluid 
Table 2. References and data of literature used in Fig. 12.

\begin{tabular}{|c|c|c|c|c|}
\hline Reference & Grain size $(\mu \mathrm{m})$ & Velocity $\left(\mathrm{m} \mathrm{s}^{-1}\right)$ & Flow depth (m) & Bedform type \\
\hline $\begin{array}{l}\text { Mastbergen \& } \\
\text { Winterwerp (1987) }\end{array}$ & 120 & $\begin{array}{l}1 \cdot 30 \\
1 \cdot 36 \\
1 \cdot 10\end{array}$ & $\begin{array}{l}0 \cdot 08 \\
0 \cdot 11 \\
0 \cdot 09\end{array}$ & $\begin{array}{l}\text { Cyclic steps } \\
\text { Cyclic steps } \\
\text { Cyclic steps }\end{array}$ \\
\hline Yokokawa et al. (2010) & 180 & $0 \cdot 85$ & $0 \cdot 05$ & Antidunes \\
\hline Guy et al. (1966) & $\begin{array}{l}190 \\
280 \\
450\end{array}$ & $\begin{array}{l}0 \cdot 88 \\
1 \cdot 23 \\
1 \cdot 16 \\
1 \cdot 06 \\
1 \cdot 45 \\
0 \cdot 91 \\
0 \cdot 62 \\
0 \cdot 75 \\
1 \cdot 53 \\
0 \cdot 76 \\
1 \cdot 46 \\
1 \cdot 63\end{array}$ & $\begin{array}{l}0 \cdot 15 \\
0 \cdot 15 \\
0 \cdot 15 \\
0 \cdot 09 \\
0 \cdot 12 \\
0 \cdot 10 \\
0 \cdot 06 \\
0 \cdot 08 \\
0 \cdot 11 \\
0 \cdot 09 \\
0 \cdot 09 \\
0 \cdot 09\end{array}$ & $\begin{array}{l}\text { Upper plane } \\
\text { Antidunes } \\
\text { Chutes-and-pools } \\
\text { Antidunes } \\
\text { Chutes-and-pools } \\
\text { Upper plane } \\
\text { Upper plane } \\
\text { Upper plane } \\
\text { Antidunes } \\
\text { Antidunes } \\
\text { Antidunes } \\
\text { Antidunes }\end{array}$ \\
\hline Gilbert (1914) & 520 & $\begin{array}{l}1 \cdot 00 \\
1 \cdot 12 \\
1 \cdot 09 \\
0 \cdot 85 \\
0 \cdot 86 \\
0 \cdot 97 \\
0 \cdot 90 \\
1 \cdot 09 \\
1 \cdot 05 \\
0 \cdot 72 \\
0 \cdot 84 \\
0 \cdot 84\end{array}$ & $\begin{array}{l}0 \cdot 05 \\
0 \cdot 06 \\
0 \cdot 07 \\
0 \cdot 06 \\
0 \cdot 08 \\
0 \cdot 08 \\
0 \cdot 08 \\
0 \cdot 07 \\
0 \cdot 05 \\
0 \cdot 09 \\
0 \cdot 09 \\
0 \cdot 06\end{array}$ & $\begin{array}{l}\text { Antidunes } \\
\text { Antidunes } \\
\text { Antidunes } \\
\text { Upper plane } \\
\text { Upper plane } \\
\text { Upper plane } \\
\text { Antidunes } \\
\text { Antidunes } \\
\text { Antidunes } \\
\text { Upper plane } \\
\text { Upper plane } \\
\text { Upper plane }\end{array}$ \\
\hline Kennedy (1961) & 550 & $\begin{array}{l}0 \cdot 95 \\
1 \cdot 01 \\
1 \cdot 01 \\
0 \cdot 79 \\
0 \cdot 64 \\
1 \cdot 31 \\
1 \cdot 07\end{array}$ & $\begin{array}{l}0 \cdot 06 \\
0 \cdot 07 \\
0 \cdot 08 \\
0 \cdot 11 \\
0 \cdot 07 \\
0 \cdot 05 \\
0 \cdot 05\end{array}$ & $\begin{array}{l}\text { Antidunes } \\
\text { Antidunes } \\
\text { Antidunes } \\
\text { Upper plane } \\
\text { Upper plane } \\
\text { Antidunes } \\
\text { Upper plane }\end{array}$ \\
\hline Alexander et al., 2001 & 420 & $\begin{array}{l}1 \cdot 16 \\
1 \cdot 30 \\
1 \cdot 37 \\
1 \cdot 41 \\
1 \cdot 50\end{array}$ & $\begin{array}{l}0 \cdot 07 \\
0 \cdot 07 \\
0 \cdot 07 \\
0 \cdot 07 \\
0 \cdot 09\end{array}$ & $\begin{array}{l}\text { Upper plane } \\
\text { Antidunes } \\
\text { Antidunes } \\
\text { Antidunes } \\
\text { Chutes-and-pools }\end{array}$ \\
\hline
\end{tabular}

properties, rather than grain size. This correlation is in contrast to the unstable bedforms (chutes-and-pools and cyclic steps), which form almost independently from Froude numbers after exceeding the Vedernikov threshold, while a rather clear distinction is seen on the basis of the mobility parameter, pointing to a more important role for particle-flow interactions.

The overall changes in hydraulic jump strength, described above, are confirmed by Fig. 13B, where ratios of $h_{90} / h_{10}$ are plotted against $F_{90}$. Figure 13B shows that the ratio of flow depths, indicative of hydraulic jump strength, increases going from antidunes to chutes-and-pools and spans a range from undular jumps to oscillating jumps. The antidune and chutes-and-pools data give a reasonable fit (Fig. 13B, $\alpha=0^{\circ}$ ) with the theoretical relation between incoming Froude number and conjugated depths of Belanger (1828), as shown in Fig. 2. The transition from chutes-and-pools to cyclic steps indicates a decreasing conjugated depth ratio. This decrease can be explained by the increasing importance of the slope break 

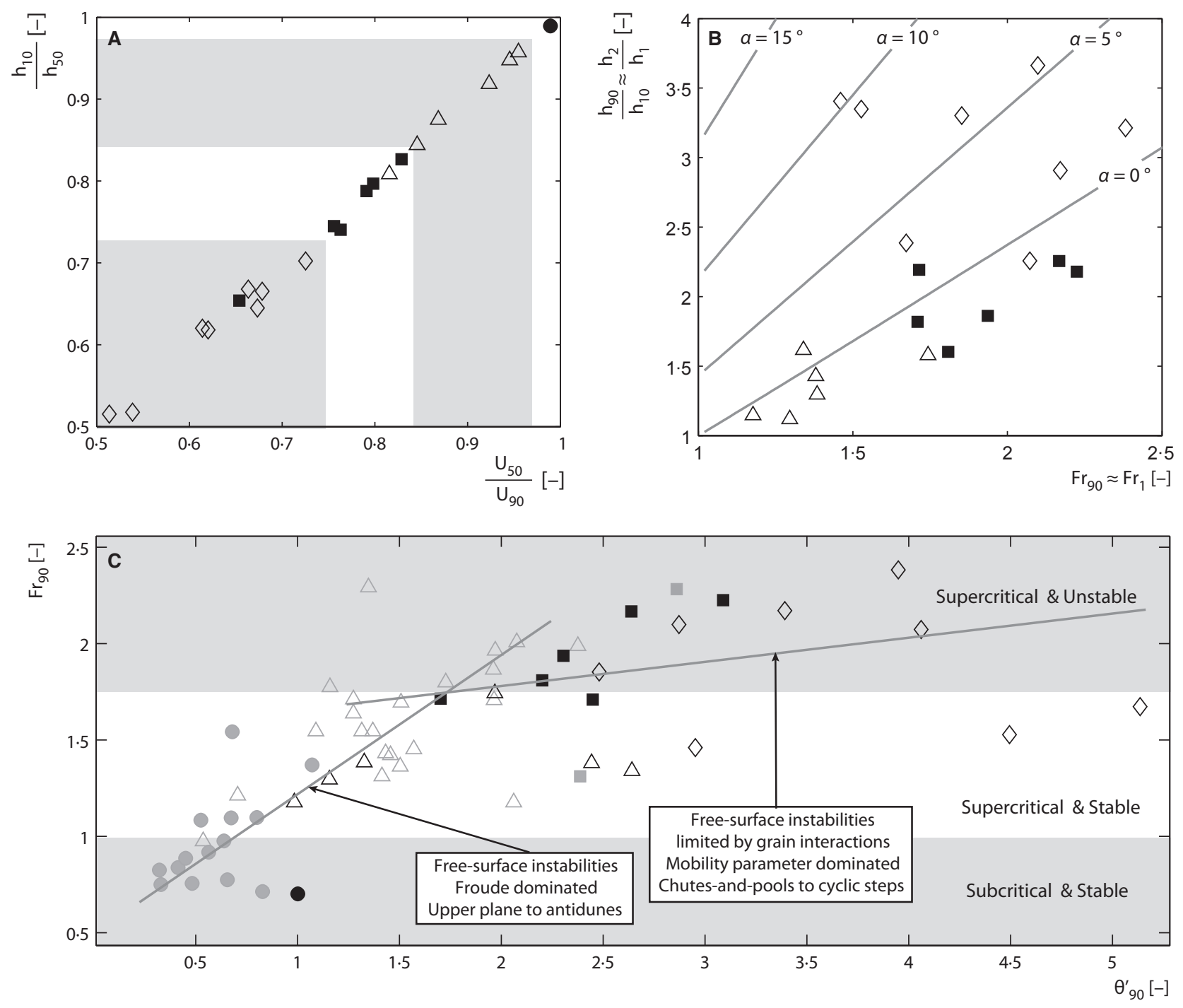

Fig. 13. (A) Ratios of $U_{50} / U_{90}$ and $h_{10} / h_{50}$ plotted per bedform and used to translate $U_{50}$ and $h_{50}$ indicated in the literature to $U_{90}$ and $h_{10}$ necessary to plot this data in Fig. 12. Symbols are as defined in Fig. 12. (B) Comparison between the ratio $h_{90} / h_{10}$ (here interpreted as a ratio of conjugated depths $h_{2} / h_{1}$ ) and theoretical (Belanger, 1828) and empirical data for hydraulic jumps on horizontal beds and submerged jumps on slope breaks of angle $\alpha$ (Fig. 2B; Hager, 1992). (C) Values of $F r_{90}$ plotted against $\theta_{90}$ ' for all data points; data trends in upper-stage plane beds and antidunes versus chutes-and-pools and cyclic steps are indicated by solid grey lines.

between the lee and stoss side, which forces a change from normal jumps to submerged jumps. Empirical relations for submerged hydraulic jumps on slope breaks (Fig. 13B, $\alpha=5$ to $15^{\circ}$ ) point to decreasing conjugated depth ratios with increasing slope break angles ( $\alpha$; Hager, 1992).

\section{Grain-size effects}

Only within the cyclic-step runs did grain size appear to have a significant effect on bedform morphology. Figure 14 compares two cyclic step runs formed at different grain sizes, discharges and mobility parameters, but similar Froude numbers (Table 1). The cyclic steps in fine sand (Fig. 14A) had a more gentle stoss side and a considerably steeper lee side than those developed in coarser sand (Fig. 14B). In the coarse-sand run most sediment settled quickly downstream of the hydraulic jump, whereas the settling rate of fine sand was lower, and was more continuously distributed over the whole stoss side, leading to gentler stoss sides.

Deposition on the stoss sides of fine-grained cyclic steps commonly took place from direct suspension fall-out (sensu Lowe, 1988) in the 


\section{A Run 1 , cyclic step fine sand $\left(D_{50}=160 \mu \mathrm{m}\right) \quad$ Flow direction}

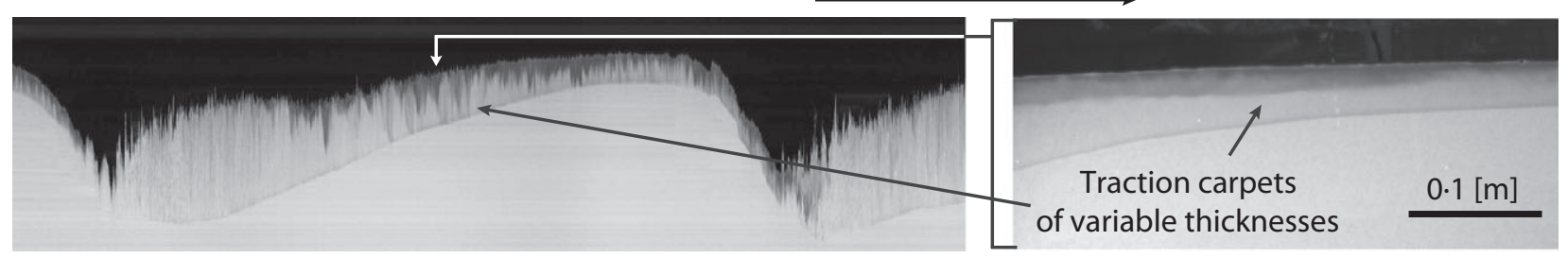

\section{B Run 9 , cyclic step medium sand $\left(D_{50}=350 \mu \mathrm{m}\right)$}

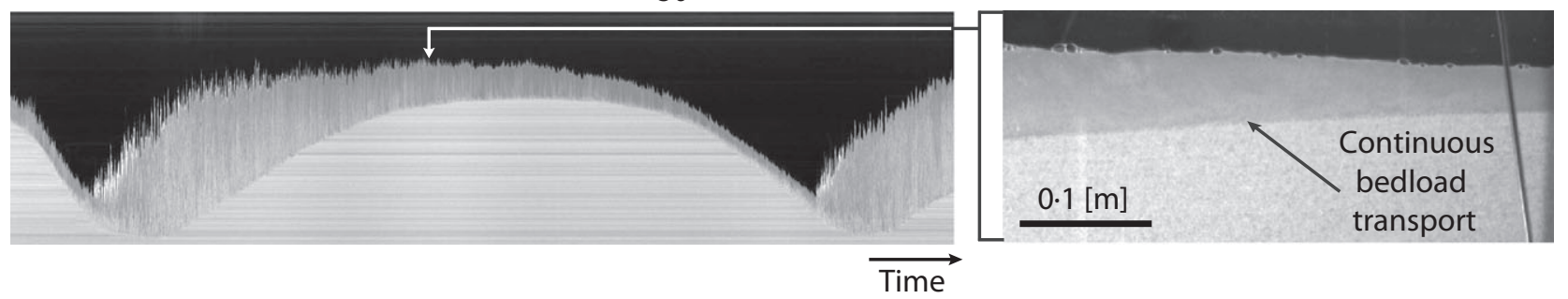

Fig. 14. (A) On the left, panorama of a cyclic step developed during Run 1, in fine sand; on the right, an image of the flow over the stoss side of the same cyclic step, showing strong stratification in sediment load (traction carpet). (B) On the left, panorama of a cyclic step developed during Run 9, in medium sand (detail of Fig. 11B); on the right; an image of the flow over the stoss side of the same cyclic step, showing continuous bedload transport. In all images, flow direction is from left to right.

proximity of the hydraulic jump forming a basal flow layer of high-sediment concentration (traction carpet) further downstream, as traction was gradually restored on the bed. As shown in the panoramic image taken during the fine-sand run (Fig. 14A), the top interface of the basal tractioncarpet layer fluctuated strongly over time; pulses of suspended sediment from the hydraulic jump settled to form traction carpets that strongly varied in thickness depending on the sediment fed from the hydraulic jump and the deposition rate below the traction carpet on the stoss side of the bedform. By contrast, deposition on coarsegrained cyclic steps mainly took place directly downstream of the hydraulic jump, forming the steepest part of the stoss side, followed quickly by minor aggradation from continuous bedload transport over the remaining portion of the stoss side.

These distinctive processes resulted in different deposits. Cyclic steps formed in fine-grained sand produce intervals of structureless sand deposited from direct particle fall-out immediately downstream of the hydraulic jump (Leclair \& Arnott, 2003; Postma et al., 2009) grading into traction-carpet deposits a little further downstream. These traction carpet deposits are characteristically faintly (or diffusely) banded (Lowe, 1982; Postma et al., 1983; Sohn, 1997;
Leclair \& Arnott, 2005; Sumner et al., 2008; Cartigny, 2012). Cyclic steps formed in medium to coarse-grained sand produce transitions from structureless hydraulic jump deposits to thinner, planar laminae as backset bedding.

Besides the gentler stoss sides, cyclic steps formed in fine sand were characterized by steeper lee sides with slopes well above the angle of repose (Fig. 15A). In the absence of sediment cohesion, such steep slopes under fast flows are often related to breaching where erosion is counteracted by negative pore pressure due to shear dilatancy (Meyer \& Van Os, 1976; Van den Berg et al., 2002; Mastbergen \& Van den Berg, 2003; Eke et al., 2011; You et al., 2012). At high shear stresses over beds of low permeability, bed deformation is associated with negative pore pressures within the sediment bed, allowing the formation of slopes beyond the angle of repose (Meyer \& Van Os, 1976). Conditions like this replace grain-to-grain erosion by progressive slide failures (Van Rhee \& Bezuijen, 1998; You et al., 2012) which transform down slope into slumps and fluidized flows, as frequently observed on the steep lee sides of cyclic steps in fine sand. Figure 15A shows a sequence of images that capture this process. Firstly, the lee side of the cyclic step steepened $\left(t_{1}-t_{2}\right)$, triggering a small-scale flow slide failure $\left(t_{3}-t_{4}\right)$. Part of this failure disinte- 

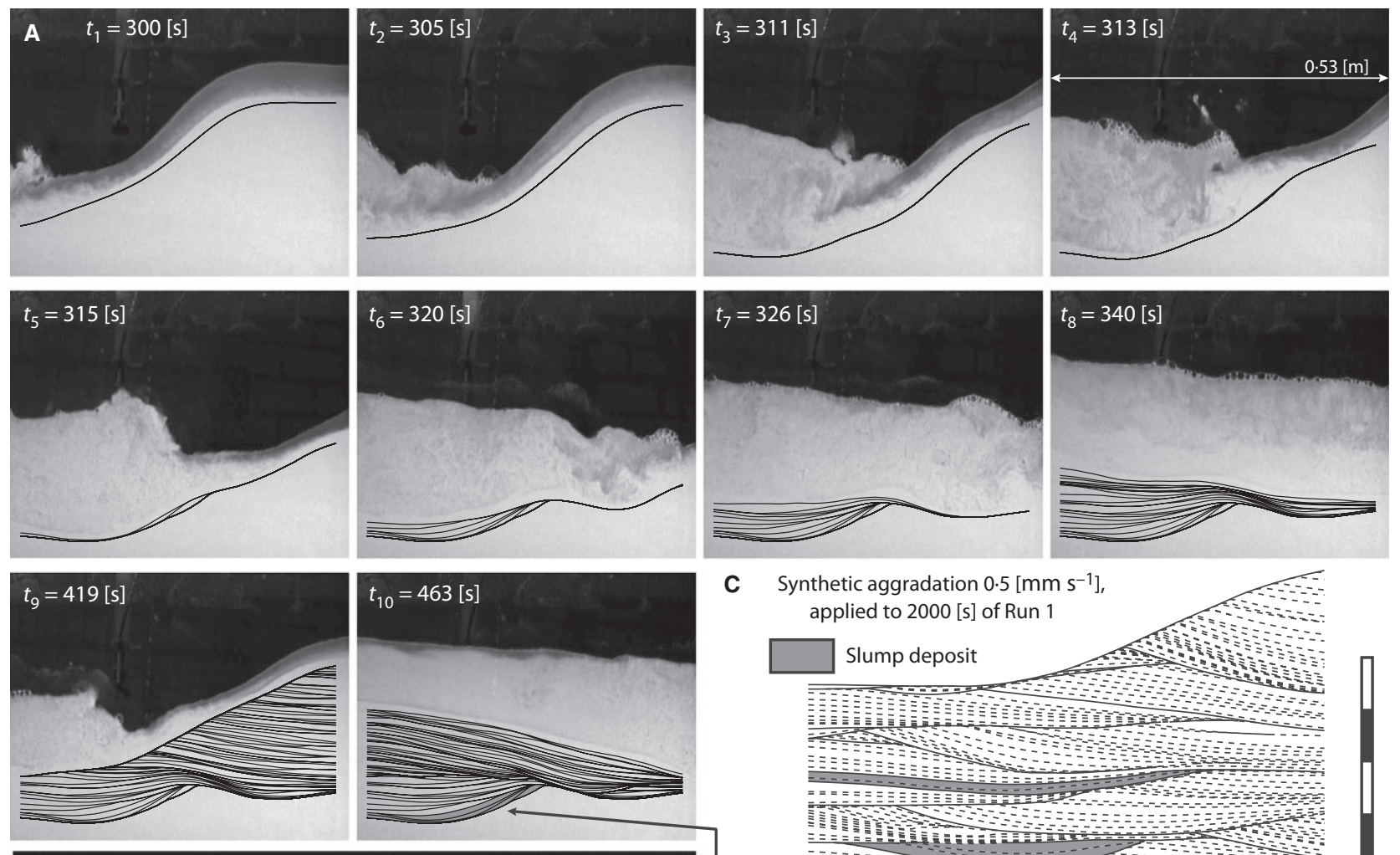

C Synthetic aggradation $0.5\left[\mathrm{~mm} \mathrm{~s}^{-1}\right.$
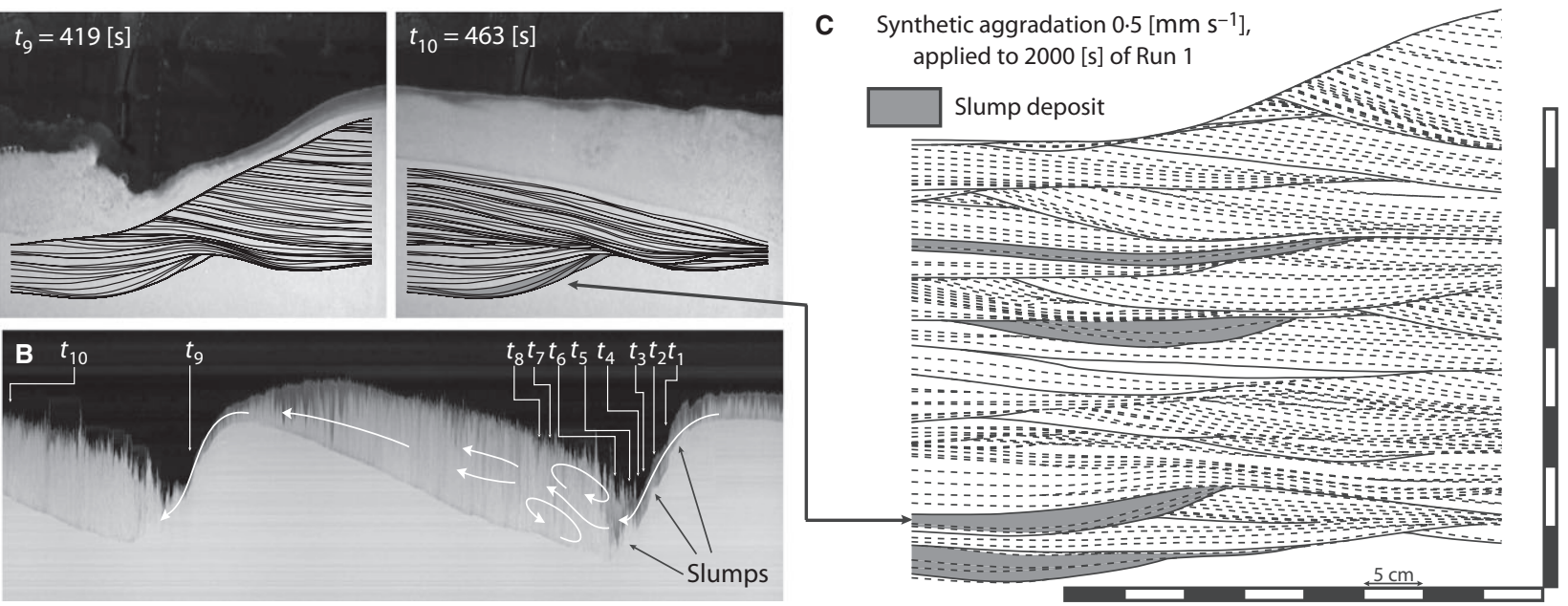

Fig. 15. Link between flow dynamics and sedimentary architecture for cyclic-step bedforms. (A) Series of images showing the development of sedimentary structures formed by slump failures on the steep lee side of a cyclic step formed during Run 1. Time, $t$, indicated in white, corresponds to the times indicated in the panoramic view in (B). Flow direction is from right to left. (B) Panorama of an active cyclic step in fine sand, showing a sequence of slumps developing on the lee side. The flow pattern is indicated by white arrows. (C) Synthetic sedimentary structures developed over the first $2000 \mathrm{~s}$ of Run 1, with an aggradation rate of $0.5 \mathrm{~mm} \mathrm{~s}{ }^{-1}$. 'Banana-shaped' deposits related to slump, triggered by liquefaction, either internally deformed or structureless, are highlighted in dark grey.

grates into a dense suspension cloud, while the remaining sediment transformed from a slide into a rotational slump, which formed a convex sedimentary structure in the adjacent trough $\left(t_{4}-t_{6}\right)$. As erosion continued on the lee side, the slump deposit became isolated from the lee side, then was overrun by the hydraulic jump and draped and preserved by rapid suspension fall-out $\left(t_{-}-t_{8}\right)$. As the flow continued, the lens-shaped slump and its structureless deposit originating from the rapid suspension fall-out was aggraded by more regular backsets $\left(t_{9}-t_{10}\right)$. These slump deposits were highlighted in grey in the synthetic aggradation profile of Fig. 15C, where spoon-shaped lamina sets similar to those developed in coarse sand were interstratified with 'banana-shaped' slump deposits.

\section{Morphodynamic relations of supercritical- flow bedforms}

The experiments indicated that antidunes and cyclic steps represented the main bedforms associated with supercritical flows. Based on their similar periods and gradual changes in morphodynamics, unstable antidunes and chutes-andpools are interpreted here as intermediate stages along the transition between antidunes and cyclic steps. Periodic fluctuations characteristic of antidune dynamics were still dominant in flow 
and bed configurations of unstable antidunes, but superimposed low-amplitude, long-wavelength cyclic-step-like fluctuations were observed (cf. Fig. 6C). On the other hand, antidune periodicities were recognizable in chutesand-pools, but here long period fluctuations more similar to cyclic steps were dominant (cf. Fig. 8C). These observations show a remarkable analogy with instabilities observed in unstable supercritical flows over non-mobile or poorly mobile beds, which initially develop small freesurface waves comparable to antidunes in mobile beds; upon breaking, such waves merge and grow into periodic surges (known as roll waves; Brock, 1967; Karcz \& Kersey,1980) similar to the periodic hydraulic jumps observed in cyclic steps. Is it thus possible that antidunes represent an incipient stage in the development of cyclic steps, and that both phenomena are different expressions of a single form of instability?

Considering antidunes and cyclic steps as main bedforms in unidirectional supercritical flows, three possible morphodynamic relations can be examined: (i) antidunes form as a primary, independent phenomenon, and only develop into secondary cyclic-step instabilities at higher flow energies $\left(\mathrm{Fr}_{90}\right)$; (ii) cyclic steps are the primary form of flow instability, initially forming through the emergence of small-amplitude, long-wavelength bedform perturbations, which trigger antidune trains; or (iii) the two flow instabilities are physically unrelated. To gain further insight into these possible relations, the driving mechanisms for both bedforms are discussed in more detail below.

Both the analogy between deep-water (wavelength $>>$ water depth) free-surface waves and antidunes (Kennedy, 1961) and the distinctive Froude-related onset of antidunes point to wave-induced fluctuations in bed shear stress as the cause of antidune formation. Cyclic steps are characterized by a typical saw-tooth-like pattern in Froude number and bed configuration; increasing Froude numbers lead to high rates of erosion and steep bedform lee sides, while sudden drops in Froude number (hydraulic jumps) are followed by protracted deposition leading to gently dipping stoss sides. The origin of the cyclic step instability thus seems to lie in the imbalance between almost instantaneous increasing erosion rates at higher bed shear stresses, in contrast to the delay time between decreasing shear stresses and deposition rates due to the time needed for the sediment to set- tle to the bed and trigger the migration of the stoss side.

Delays between changes in flow properties and sediment transport rates have been fundamental in the study of the dynamics of bedforms. The lag distance between sediment transport rates to changes in flow properties has been explored with stability analysis by many authors over the last decades (Kennedy, 1963, 1969; Engelund, 1970; Fredsøe, 1974; Parker, 1975; Coleman \& Fenton, 2000; Colombini, 2004; Colombini \& Stocchino, 2005). Other authors (McLean, 1990; Zhou \& Mendoza, 2005; Venditti et al., 2006) have, however, pointed to a possible gap in between initial lag distances, their small-amplitude bedform expressions and the ultimate equilibrium geometry. Without theoretical constraints and spatial measurements, the experiments here showed that runs with increasing $\mathrm{Fr}_{90}$ numbers showed larger velocity fluctuations and longer stretches of enhanced deposition, which eventually formed the stoss sides of cyclic steps. This observation seems to hint at the possibility that antidunes are the primary bedforms related to flow instabilities caused by free-surface waves of supercritical flows and, with increasing energy, these instabilities trigger longer, incipient cyclic-step instabilities as lag distances start to exceed antidune wavelengths.

Recent numerical work, however, has shown that cyclic steps could be considered the primary instability for flows exceeding $F r=1$ (Balmforth \& Vakil, 2012). These numerical simulations revealed secondary instabilities that resemble antidunes in wavelength and dynamics, pointing to cyclic steps as the primary bedform. Therefore, numerical simulations seem to suggest that antidunes could be a secondary form of flow instability triggered by variations in Froude number resulting from incipient cyclic steps. In the framework of this alternative hypothesis, trains of surface waves (antidunes) separated by areas of upper-stage plane beds could be considered as undulating jumps on very low-amplitude, incipient cyclic steps. This hypothesis has the advantage of explaining the initial variations in antidune amplitude (trains), which remain unexplained by the first hypothesis above. However, the flume measurements showed that antidunes indeed formed under continuous supercritical flow, which contradicts the second hypothesis. More detailed measurements over time and along the entire flow length, instead of measurements at fixed positions, are necessary to further address this aspect. 


\section{Implications for recognition in the rock record}

Sedimentary structures linked to supercriticalflow bedforms have been observed in outcrops and present-day environments from a wide range of depositional settings, such as alluvial and fluvial systems (e.g. Van den Berg et al., 1997; Fralick, 1999; Blair, 1999, 2000; Fielding, 2006), proglacial systems (e.g. Duller et al., 2008), glaciolacustrine subaqueous fans (e.g. Postma et al., 1983; Russell \& Arnott, 2003; Hornung et al., 2007; Russell et al., 2007), turbidite systems (e.g. Prave \& Duke, 1990; Fildani et al., 2006; Heinio \& Davies, 2009; Mulder et al., 2009; Straub \& Mohrig, 2009; Paull et al., 2011; Gong et al., 2012) often referred to as hummocky cross-stratified like structures (Prave \& Duke, 1990; Mulder et al., 2009) and volcanic environments (e.g. Schmincke et al., 1973; Sisavath et al., 2011). Process interpretations of bedforms and structures have been supported by previous experimental work (Middleton, 1965; Hand, 1974; Alexander et al., 2001; Yokokawa et al., 2010). Figure 16 provides a comparative simplified overview of outcrop-based classification schemes and experimental work discussed in the literature. Most of this work has recog-

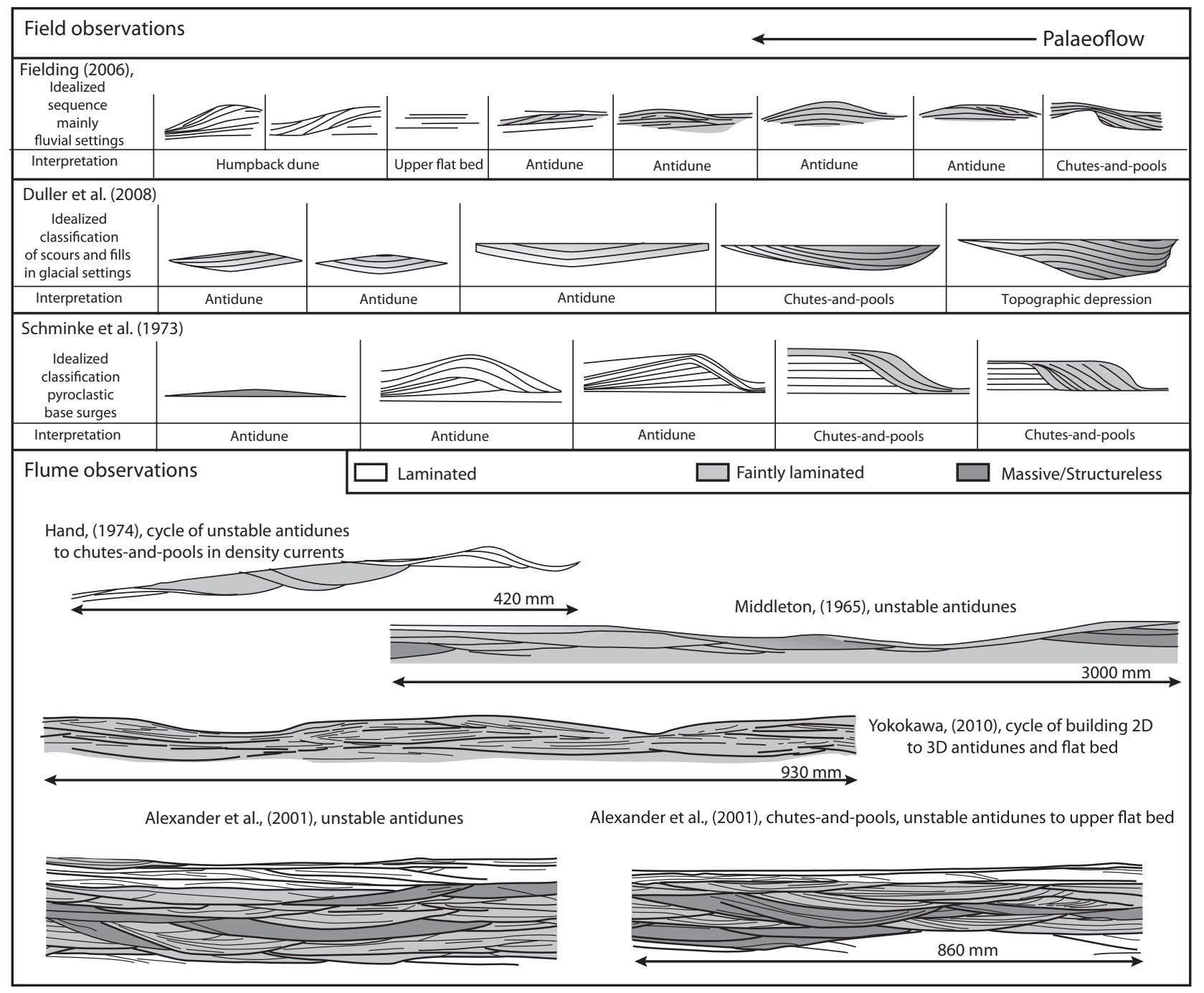

Fig. 16. Sedimentary structures in the literature on supercritical-flow bedforms, from previous experimental work and outcrop examples from alluvial (Fielding, 2006), proglacial (Duller et al., 2008) and volcanic settings (Schmincke et al., 1973). The bottom panel shows sedimentary structures associated with supercritical flows, including structures formed by supercritical saline underflows over crushed coal beds (Hand, 1974), antidunes and chutes-and-pools formed by supercritical flows on sand beds (Middleton,1965; Alexander et al., 2001; Yokokawa et al., 2010). 
nized antidunes and chutes-and-pools, but cyclic steps started to be mentioned only recently (e.g. Duller et al., 2008; Heinio \& Davies, 2009); due to a lack of experimental work on their sedimentary structures, the recognition of this latter bedform has been very uncertain to date.

Even though observations from this variety of environmental settings differ substantially, some general trends in facies architectures can be recognized. Starting from cross-bedded foreset beds associated with dunes and ripples in subcritical flows, and moving into higher energy settings, the remaining general architectural trend is divided into six general classes of stratal architectures, each of which will be discussed separately: (i) subhorizontal plane beds; (ii) scours filled with planar to sigmoidal foresets; (iii) plane beds interstratified with lenticular bedding and a mix of foreset and backset bedding; (iv) lenticular bedding with pronounced convexup tops and associated backsets; (v) elongated lenticular bedding with diffusely banded sediments, grading vertically or downflow into more distinctly laminated deposits; and (vi) large-scale, steep-sided scours with structureless basal infills, grading into more diffusely banded deposits. This sequence of increasing flow energy is usually associated with coarsening upward grain-size trends.

\section{Subhorizontal plane beds}

Subhorizontal to low-angle planar millimetrescale stratification and metre-scale lateral continuity are well-known to be characteristic of upper-stage (subcritical) plane beds (Paola et al., 1989; Cheel, 1990; Best \& Bridge, 1992). Such planar lamination has been experimentally shown to correspond to low-relief bedwaves (Bridge \& Best, 1988; Bennett et al., 1998; Yagisita et al., 2004). Alternatively, plane beds consisting of sandygravelly couplets have also been interpreted as violent washout of breaking antidunes immediately followed by reworking under less turbulent conditions, based on both field and flume evidence (Iseya \& Ikeda, 1987; Blair, 1999, 2000). It is noted here that these plane beds are very similar to those produced by stable antidunes under low aggradation rates (Run 11, Fig. 5D), making their genetic interpretation difficult.

Scours filled with planar to sigmoidal foresets Scours filled with sigmoidal foreset laminae can be interpreted as the product of downstreammigrating antidunes (Barwis \& Hayes, 1985; Cheel, 1990; Blair, 1999; Duller et al., 2008) or of dunes with distinctly rounded tops (humpback dunes), which are known to form at flow transitions between dunes and upper-stage plane beds (e.g. Saunderson \& Lockett, 1983; Røe, 1987; Fielding, 2006). Downstream-dipping laminae have been observed to result from rapid downstream migration of asymmetrical bedforms generated immediately after the breaking of surface waves (Alexander et al., 2001). The experimental observations reported here suggest two additional explanations for the occurrence of sigmoidal foreset laminae under supercritical-flow conditions. Firstly, as previously mentioned, basal lamina sets from unstable antidunes showed variable dip, depending on the extent of upstream migration of the positive surge triggered by breaking waves. Sigmoidal foresets here have been observed mainly in deeper incised troughs (Fig. 6A, $t_{1}-t_{4}$ ) related to the most violent wavebreaking events, and thereby to surges reaching furthest upstream. Low-angle sigmoidal foresets produced by this mechanism tend to be conformable to set boundaries (for example, lenticular and tabular bed sets of Duller et al., 2008; Fig. 16). Secondly, reworking of symmetrical convex-up structures typical for chutes-and-pools lead to sigmoidal foresets (Fig. 8A, $t_{5}-t_{6}$ ).

\section{Lenticular sets filled with boundary- conformable laminae}

Lenticular units consisting of associated foreset and backset laminae are characteristic of both unstable antidunes and chutes-and-pools (Middleton, 1965; Hand, 1974; Alexander et al., 2001; Fielding, 2006; Duller et al., 2008). Chute-andpool deposits, however, can be distinguished from those of unstable antidunes by their prevalent lack of internal structure and lamination (Alexander et al., 2001). Sedimentary structures described here have confirmed these observations, and have also shown that chutes-and-pools can produce convex, conformable lamina sets at high aggradation rates (Fig. 9B and C).

\section{Lenticular sets with convex tops}

Lenticular lamina sets with convex tops have been recognized in outcrops (e.g. Schmincke et al., 1973; Fielding, 2006), as well as in experimental work. Alexander et al. (2001) observed convex laminae associated with stationary surface waves. The experiments of the present paper confirmed this observation and showed that pronounced convex-top lamina sets increased in curvature at higher flow energies, reaching a maximum in chute-and-pool structures. The syn- 
thetic aggradation technique indicated that preservation of these convex tops is only likely at high aggradation rates. Outcrop examples of convex lamina sets (Fielding, 2006) indicated that high aggradation rates should not be uncommon under supercritical-flow conditions in natural settings, in contrast to the commonly held opinion that such flows should be expected to be mainly erosive or non-depositional. The resemblance of unstable antidune deposits and hummocky cross-stratification has been previously discussed in the literature in relation to turbidity current deposits (e.g. Pickering \& Hiscott, 1985; Prave \& Duke, 1990; Mutti et al., 1996; Myrow et al., 1998; Alexander et al., 2001; Mulder et al., 2009; Tinterri, 2011) and is confirmed by the experiments described in this paper to become even stronger for chute-and-pool structures formed under high aggradation rates, where sets of swaley laminae are observed (Fig. $8, t_{5}-t_{7}$ ).

Elongated lenticular scours filled with diffusely banded sediment

Elongated, lenticular and spoon-shaped scours filled by diffusely banded sediments which grade vertically or downstream into distinctly laminated deposits have been associated with chuteand-pool structures or cyclic steps in outcrop observations (Fielding, 2006; Duller et al., 2008). Experiments by Yokokawa et al. (2009) showed that cyclic steps form lens-shaped units with low aspect-ratios that are filled with both massive sand and backset laminae. These descriptions match the observations reported here. The internal geometry of these elongated units varies with the flow processes associated with cyclic step formation. Next to backset lamination observed by Yokokawa et al. (2009) and in the above experiments, laminae more distinctly conformable to set boundaries were observed in cases where the hydraulic jump was positioned furthest upstream on the lee side of the cyclic step, at its maximum distance from the trough. Transitions of structureless deposits to diffusely banded or more distinctly laminated deposits (see Postma et al., 1983, for examples) could correspond to the formation of either collapsing traction carpets or continuous bedload layers.

Steep-sided scours with structureless basal fills grading into diffusely banded deposits The preservation of steep-sided scours is often associated with the infill of topographic depressions or to flow scouring around obstacles (Massari, 1996; Duller et al., 2008). The observations of the present study showed that lee sides of cyclic steps can acquire very steep angles, due to the dilatant properties of fine sand. However, as seen in the experiments, the preservation potential of steep lee sides was very low. Thus, topographic depressions or obstacle scours are a more reasonable interpretation. The steep-sided, U-shaped channels with structureless basal fills were explained by Postma et al. (1983) to originate from local slumping and subsequent plugging by the resultant liquefied sand flow; in a similar way, slumping processes observed in fine-sand cyclic steps (Fig. 15) could lead to the preservation of steep-sided scours.

\section{CONCLUSIONS}

Flume experiments were conducted to investigate the morphodynamics and sedimentary structures of bedforms under supercritical-flow conditions. The following insights were gained from a combination of qualitative and quantitative observations on supercritical-flow bedforms developing in the complete range from incipient antidunes to cyclic steps:

1 Antidunes, unstable antidunes, chutes-andpools and cyclic steps are mutually transitional bedforms. With increasing peak Froude numbers, short-wavelength bedforms of antidunes gradually transform into longer wavelength bedforms, called cyclic steps. The unstable antidunes and chutes-and-pools represent a superposition of both bedforms, with antidunes being dominant in the unstable antidunes runs, and cyclic steps being dominant in the chutes-and-pools runs.

2 Classical bedform stability diagrams have been expanded to include the various kinds of supercritical bedforms observed under different flow conditions. In these diagrams, the onset of antidunes shows a Froude-number-related threshold, while the onset of cyclic steps is related to a modified particle-mobility parameter threshold. The latter indicates a dominant role for flow-particle interactions, in contrast to the onset of antidunes, which is only related to flow properties.

3 Sediment grain size has a significant impact on the geometry of cyclic steps and on the processes regulating cyclic step dynamics. Fine sand leads to gently sloping stoss sides formed under tractionless sediment settling due to the hydraulic jump gradually transforming downstream into depositional high-density basal lay- 
ers, while the lee sides are steep under the influence of shear dilatancy. Medium sand leads to initially steeper stoss sides formed under settling conditions similar to those for fine sand, but followed downstream by more gently sloping stoss sides formed under normal bedload conditions. By contrast, the dynamics of antidunes do not show any dependence on grain size.

4 The analysis of synthetic bedform architectures highlights the importance of varying aggradation rates for the geometry and preservation of supercritical-flow structures, and thus for their identification in successions formed under different conditions. Although cyclic steps appear to be relatively less sensitive to this variable, the internal architecture of antidunes and chuteand-pool structures is relatively dampened or amplified with changes from low to high aggradation rates. For example, antidunes developed under particularly low aggradation rates may morphologically resemble plane beds; chuteand-pool structures aggraded under high depositional rates may be misinterpreted as hummocky cross-stratification, whereas they may resemble unstable-antidune deposits or trough crossbedding when formed at low aggradation rates.

\section{ACKNOWLEDGEMENTS}

This research was supported by NWO (Netherlands Organization for Scientific Research) grant 816.01.006. D. Ventra was supported by grant NWO-ALW 815.01.012. The authors thank Wouter Poos for carrying out part of the experimental work. Thony van der Gon Netscher and Henk van der Meer are thanked for their technical support at the Eurotank Laboratory. Poppe de Boer and Leo van Rijn are acknowledged gratefully for their critical reading of an earlier version of the manuscript. We also thank Jan Alexander, Paul Carling, Suzanne Leclair and Associate Editor Jeremy Venditti for their constructive reviews.

\section{REFERENCES}

Alexander, J. and Fielding, C. (1997) Gravel antidunes in the tropical Burdekin River, Queensland, Australia. Sedimentology, 44, 327-337.

Alexander, J., Bridge, J.S., Cheel, R.J. and Leclair, S.F. (2001) Bedforms and associated sedimentary structures formed under water flows over aggrading sand beds. Sedimentology, 48, 133-152.
Allen, J.R.L. (1982) Sedimentary Structures. Their Character and Physical Basis, Vol. 1. Elsevier, Amsterdam, 593 pp.

Allen, J.R.L. (1985) Loose-boundary hydraulics and fluid mechanics: Selected advances since 1961. In: Sedimentology - Recent Developments and Applied Aspects (Eds P.J. Brenchley and B.P.J. Williams), Geol. Soc. London, Spec. Publ., 18, 7-28.

Augustinus, P.G.E.F. (1980) Actual development of the Chenier Coast of Suriname. Sed. Geol., 26, 91-113.

Balmforth, N.J. and Mandre, S. (2004) Dynamics of roll waves. J. Fluid Mech., 514, 1-33.

Balmforth, N.J. and Vakil, A. (2012) Cyclic steps and roll waves in shallow water flow over an erodible bed. J. Fluid Mech., 695, 35-62.

Barwis, J.H. and Hayes, M.O. (1985) Antidunes on modern and ancient washover fans. J. Sed. Petrol., 55, 907-916.

Belanger, J.B. (1828) Essai sur la solution numérique de quelques problèmes relatifs au mouvement permanent des eaux courantes. Carilian-Goeury, Paris, France.

Bennett, S.J., Bridge, J.S. and Best, J.L. (1998) Fluid and sediment dynamics of upper stage plane beds. J. Geophys. Res., 103(C1), 1239-1274.

Best, J.L. (1993) On the interactions between turbulent flow structure, sediment transport and bedform development: Some considerations from recent experimental research. In: Turbulence: Perspectives on Flow and Sediment Transport, pp. 61-92. (Eds N.J. Clifford, J.R. French and J. Hardisty), John Wiley \& Sons, Chichester, UK.

Best, J.L. (1996) The fluid dynamics of small-scale alluvial bedforms. In: Advances in Fluvial Dynamics and Stratigraphy, pp. 67-125. (Eds P.A. Carling and M.R. Dawson), John Wiley \& Sons Ltd., Chichester, UK.

Best, J. and Bridge, J. (1992) The morphology and dynamics of low amplitude bedwaves upon upper stage plane beds and the preservation of planar laminae. Sedimentology, 39, 737-752.

Blair, T.C. (1987) Sedimentary processes, vertical stratification sequences, and geomorphology of the Roaring River alluvial fan, Rocky Mountain National Park, Colorado. J. Sed. Petrol., 57, 1-18.

Blair, T.C. (1999) Sedimentary processes and facies of the waterlaid Anvil Spring Canyon alluvial fan, Death Valley, California. Sedimentology, 46, 913-940.

Blair, T.C. (2000) Sedimentology and tectonic unconformities of the sheetflood-dominated Hell's Gate alluvial fan, Death Valley, CA. Sed. Geol., 132, 233-262.

Bonnefille, R. (1963) Essais de synthese des lois du début d'entrainement des sédiments sous l'action d'un courant en regime continu. Bull. du Centre de Rech. et d'ess. de Chatou, 5, 17-22.

Bradley, J.N. and Peterka, A.J. (1955) Research study on stilling basins, energy dissipators and associated appurtenances. U.S. Bureau of Reclamation, Hydraulic Laboratory Report, HYD-399.

Bridge, J.S. and Best, J.L. (1988) Flow, sediment transport and bedform dynamics over the transition from dunes to upper-stage plane beds: Implications for the formation of planar laminae. Sedimentology, 355, 753-763.

Brock, R.R. (1967) Development of Roll Waves in Open Channels. W. M. Keck Laboratory of Hydraulic and Water Research, California Institute of Technology, Report KH-R16, 226 pp.

Broome, R. and Komar, P.D. (1979) Undular hydraulic jumps and the formation of backlash ripples on beaches. Sedimentology, 264, 543-559. 
Carling, P.A. and Breakspear, R.M.D. (2007) Gravel dunes and antidunes in fluvial systems. In: River, Coastal and Estuarine Morphodynamics: RCEM 2007 (Eds C.M. Dohmen-Janssen and S.J.M.H. Hulscher), pp. 1015-1020. Taylor \& Francis Group, London.

Carling, P.A. and Schvidchenko, A.B. (2002) A consideration of the dune-antidune transition in fine gravel. Sedimentology, 49, 1269-1282.

Cartigny, M.J.B. (2012) Morphodynamics of supercritical high-density turbidity currents. Utrecht Studies in Earth Sciences, 10, 153 pp.

Cartigny, M.J.B., Postma, G., Van Den Berg, J.H. and Mastbergen, D.R. (2011) A comparative study of sediment waves and cyclic steps based on geometries, internal structures and numerical modeling. Mar. Geol., 280, 40-56.

Chanson, H. (2002) The Hydraulics of Open Channel Flow. Butterworth-Heinemann, Oxford.

Chanson, H. (2009) Current knowledge in hydraulic jumps and related phenomena. A survey of experimental results. Eur. J. Mech. B - Fluids, 28, 191-210.

Cheel, R.J. (1990) Horizontal lamination and the sequence of bed phases and stratification under upper-flow-regime conditions. Sedimentology, 37, 517-529.

Chow, Ven Te (1959) Open-channel Hydraulics. McGrawHill Book, New York.

Coleman, S.E. and Fenton, J.D. (2000) Potential-flow instability theory and alluvial stream bed forms. J. Fluid Mech., 418, 101-117.

Colombini, M. (2004) Revisiting the linear theory of sand dune formation. J. Fluid Mech., 502, 1-16.

Colombini, M. and Stocchino, A. (2005) Coupling or decoupling bed and flow dynamics: Fast and slow sediment waves at high Froude numbers. Phys. Fluids, 17, 036602.

Corea, W.C. (1978) A method for synthesizing sedimentary structures generated by migrating bedforms. Unpublished S. M. thesis, Massachusetts Institute of Technology, Boston, $58 \mathrm{pp}$.

Cornish, V. (1910) Waves of the Sea and Other Water Waves. Unwin, London.

Devauchelle, O., Malverti, L., Lajeunesse, E., Josserand, C., Lagrée, P.Y. and Métivier, F. (2010a) Rhomboid beach pattern: A laboratory investigation. J. Geophys. Res., series F, 115, F02017, doi:10.1029/2009JF001471.

Devauchelle, O., Malverti, L., Lajeunesse, E., Lagrée, P.Y., Josserand, C. and Nguyen Thu-Lam, K.D. (2010b) Stability of bedforms in laminar flows with free-surface: From bars to ripples. J. Fluid Mech., 642, 329-348.

Duller, R.A., Mountney, N.P., Russell, A.J. and Cassidy, N.C. (2008) Architectural analysis of a volcaniclastic jökulhlaup deposit, southern Iceland: Sedimentary evidence for supercritical flow. Sedimentology, 55, 939-964.

Dumas, S., Arnott, R.W.C. and Southard, J.B. (2005) Experiments on oscillatory-flow and combinedflow bed forms: Implications for interpreting parts of the shallow marine rock record. J. Sed. Res., 75, 501-513.

Eke, E., Viparelli, E. and Parker, G. (2011) Field-scale numerical modeling of breaching as a mechanism for generating continuous turbidity currents. Geosphere, 75, 1063-1076.

Emery, W.J. and Thomson, R.E. (1998) Data Analysis Methods in Physical Oceanography. Pergamon, Oxford, UK, $634 \mathrm{pp}$.

Engelund, F. (1970) Instability of erodible beds. J. Fluid Mech., 42, 225-244.
Fagherazzi, S. and Sun, T (2003) Numerical simulations of transportational cyclic steps. Comput. Geosci., 29, 11431154.

Fielding, C.R. (2006) Upper flow regime sheets, lenses and scour fills: Extending the range of architectural elements for fluvial sediment bodies. Sed. Geol., 190, 227-240.

Fildani, A., Normark, W.R., Kostic, S. and Parker, G. (2006) Channel formation by flow stripping: Large-scale scour features along the Monterey East Channel and their relation to sediment waves. Sedimentology, 53, 1265-1287.

Fralick, P. (1999) Paleohydraulics of chute-and-pool structures in a Paleoproterozoic fluvial sandstone. Sed. Geol., 125, 129-134.

Fredsøe, J. (1974) On the development of dunes in erodible channels. J. Fluid Mech., 64, 1-16.

Fredsøe, J. and Engelund, F. (1975) Bed configuration in open and closed alluvial channels. Ser. Pap. Inst. Hydrodynamics Hydraul. Eng. Tech. Univ. Denmark, 8, 1-39.

Fukuoka, S., Okutsu, K. and Yamasaka, M. (1982) Dynamics and kinematic features of sand waves in upper regime. (In Japanese). Proc. Jpn Soc. Civ. Eng, 323, 77-89.

Gilbert, G. K. (1914) The transportation of débris by running water. U.S. Geol. Surv. Prof. Pap., 86, 263 pp.

Gong, C., Wang, Y., Peng, X., Li, W., Qiu, Y. and Xu, S. (2012) Sediment waves on the South China Sea Slope off southwestern Taiwan: Implications for the intrusion of the Northern Pacific Deep Water into the South China Sea. Mar. Petrol. Geol., 321, 95-109.

Guy, H. P., Simons, D. B. and Richardson, E. V. (1966) Summary of alluvial channel data from flume experiments 1956-1961. U.S. Geol. Surv. Prof. Paper, 462-I, 96 pp.

Hager, W.L. (1992) Energy Dissipators and Hydraulic Jumps. Kluwer Academic Publishers, Dordrecht.

Hand, B.M. (1974) Supercritical flow in density currents. J. Sed. Petrol., 44, 637-648.

Heinio, P. and Davies, R.J. (2009) Trails of depressions and sediment waves along submarine channels on the continental margin of Espirito Santo Basin. Brazil. Geol. Soc. Am. Bull., 121, 698-711.

Hornung, J.J., Asprion, U. and Winsemann, J. (2007) Jet-efflux deposits of a subaqueous ice-contact fan, glacial Lake Rinteln, northwestern Germany. Sed. Geol., 193, 167-192.

Iseya, F. and Ikeda, H. (1987) Pulsation in bedload transport rates induced by a longitudinal sediment sorting: A flume study using sand and gravel mixtures. Geogr. Ann., 69, $15-27$.

Jeffreys, H.J. (1925) The flow of water in an inclined channel of rectangular section. Phil. Mag., 6, 793-807.

Jopling, A.V. and Richardson, E.V. (1966) Backset bedding developed in shooting flow in laboratory experiments. J. Sed. Petrol., 36, 821-825.

Karcz, I. and Kersey, D. (1980) Experimental study of freesurface flow instability and bedforms in shallow flows. Sed. Geol., 27, 263-300.

Kennedy, J.F. (1961) Stationary Waves and Antidunes in Alluvial Channels. W.M. Keck Laboratory of Hydraulics and Water Research, California Institute of Technology, Report KH-R-2, 146 pp.

Kennedy, J.F. (1963) The mechanics of dunes and antidunes in erodible-bed channels. J. Fluid Mech., 16, 521-544.

Kennedy, J.F. (1969) The formation of sediment ripples, dunes and antidunes. Ann. Rev. Fluid Mech., 1, 147-168.

Koloseus, H.J. and Davidian, J. (1966) Free surface instabilities correlations. U.S. Geol. Surv. Water-Sup. Pap., 1592-C, $72 \mathrm{pp}$. 
Kostic, S. (2011) Modeling of submarine cyclic steps: Controls on their formation, migration, and architecture. Geosphere, 7, 294-304.

Kostic, S. and Parker, G. (2006) The response of turbidity currents to a canyon-fan transition: Hydraulic jumps and depositional signatures. J. Hydraul. Res., 44, 631-653.

Kostic, S., Sequeiros, O., Spinewine, B. and Parker, G. (2010) Cyclic steps: A phenomenon of supercritical shallow flow from the high mountains to the bottom of the ocean. J. Hydro-environ. Res., 3, 167-172.

Lamb, M.P., Parsons, J.D., Mullenbach, B.L., Finlayson, D.P., Orange, D.L. and Nittrouer, C.A. (2008) Evidence for superelevation, channel incision, and formation of cyclic steps by turbidity currents in Eel Canyon, California. Geol. Soc. Am. Bull., 120, 463-475.

Langford, R. and Bracken, B. (1987) Medano Creek, Colorado, a model for upper-flow-regime fluvial deposition. J. Sed. Petrol., 55, 863-870.

Leclair, S.F. and Arnott, R.W.C. (2003) Coarse-tail graded, structureless strata: Indicators of an internal hydraulic jump. In: Shelf Margin Deltas and Linked Down Slope Petroleum Systems: Global Significance and Future Exploration Potential (Eds H.H. Roberts, N.C. Rosen, R.H. Filion and J.B. Anderson), pp. 817-836. SEPM Gulf Coast Section, Houston.

Leclair, S.F. and Arnott, R.W.C. (2005) Parallel lamination formed by high-density turbidity currents. J. Sed. Res. 75(1), $1-5$.

Leeder, M.R. (1983) On the interactions between turbulent flow, sediment transport and bedform mechanics in channelized flows. In: Modern and Ancient Fluvial Systems (Eds. J.D. Collinson and J. Lewin), Int. Assoc. Sedimentol. Sp. Publ., 6, 5-18.

Lennon, J.M. and Hill, D.F. (2006) Particle image velocimetry measurements of undular and hydraulic jumps. J. Hydr. Eng., 132, 1283-1294.

Lighthill, J. (1978) Waves in Fluids. Cambridge University Press, Cambridge, 516 pp.

Long, D., Steffler, P.M., Rajaratnam, N. and Smy, P. (1991) Structure of flow in hydraulic jumps. J. Hydraul. Res., 29, 293-308.

Lowe, D.R. (1982) Sedimentary gravity flows: II. Depositional models with special reference to the deposits of high density turbidity currents. J. Sed. Petrol., 52, 279-297.

Lowe, D.R. (1988) Suspended-load fall-out rate as an independent variable in the analysis of current structures. Sedimentology, 35, 765-776.

MacDonald, R.G., Alexander, J., Bacon, J.C. and Cooker, M.J. (2009) Flow patterns, sedimentation and deposit architecture under a hydraulic jump on a non-eroding bed: Defining hydraulic-jump unit bars. Sedimentology, 56, 1346-1367.

Massari, F. (1996) Upper-flow-regime stratification types on steep-face, coarse-grained, Gilbert-type progradational wedges. J. Sed. Res., 66, 364-375.

Mastbergen, D.R. and Van den Berg, J.H. (2003) Breaching in fine sands and the generation of sustained turbidity currents in submarine canyons. Sedimentology, 50, 625-637.

Mastbergen, D.R. and Winterwerp, J.C. (1987) Het gedrag van zand-watermengselstromingen boven water: Verslag experimentele vervolg studie. Report Z46-02, Delft Hydraulics, Delft, The Netherlands.

McKee, E.D., Crosby, E.J. and Berryhill, H.L. (1967) Flood deposits, Bijou Creek, Colorado, June 1965. J. Sed. Petrol., 37, 829-851.
McLean, S.R. (1990) The stability of ripples and dunes. Earth-Sci. Rev., 19, 131-144.

Meyer, K.L. and Van Os, A.G. (1976) Pore pressures near moving underwater slope. J. Geotech. Eng. Div. Am. Soc. Civ. Eng., 102, 361-372.

Middleton, G.V. (1965) Antidune cross-bedding in a large flume. J. Sed. Petrol., 35, 922-927.

Middleton, G. V. and Southard, J. B. (1984) Mechanics of sediment movement. Society of Economic Paleontologists and Mineralogists Short Course 3, 401 pp.

Montes, J.S. (1986) A Study of the Undular Jump Profile. Proc. 9th Australasian Fluid Mechanics Conference AFMC, Auckland, New Zealand, pp. 148-151.

Mulder, T., Razin, P. and Faugères, J.C. (2009) Hummocky cross-stratification-like structures in deep-sea turbidites: Upper Cretaceous Basque basins (Western Pyrenees, France). Sedimentology, 56, 997-1015.

Mutti, E., Davoli, G., Tinterri, R. and Zavala, C. (1996) The importance of ancient fluvio-deltaic systems dominated by catastrophic flooding in tectonically active basins. Sci. Geol. Mem., 48, 232-291.

Myrow, P.M., Lukens, C., Lamb, M.P., Houck, K. and Strauss, J. (1998) Dynamics of a transgressive prodeltaic system: Implications for geography and climate within a Pennsylvanian intracratonic basin, Colorado, USA. J. Sed. Res., 78, 512-528.

Newitt, D.M., Richardson, J.F., Abbott, M. and Turtle, R.B. (1955) Hydraulic conveying of solids in horizontal pipes. Trans. Inst. Chem. Engrs., 33, 93-113.

Normark, W.R., Hess, G.R., Stow, D.A.V. and Bowen, A.J. (1980) Sediment waves on the Monterey Fan levee: A preliminary physical interpretation. Mar. Geol., 37, 1-18.

Paola, C., Wiele, S.M. and Reinhart, M.A. (1989) Upperregime parallel lamination as the result of turbulent sediment transport and low-amplitude bedforms. Sedimentology, 36, 47-59.

Parker, G. (1975) Sediment inertia as cause of river antidunes. J. Hydraul. Div. ASCE, 101, 211-221.

Parker, G. (1996) Some speculations on the relation between channel morphology and channel-scale flow structures. In: Coherent Flow Structures in Open Channels (Eds P.J. Ashworths, S.J. Bennett, J.L. Best and S.J. McLelland), pp. 423-458. John Wiley \& sons, New York.

Paull, C.K., Caress, D.W., Ussler, W., Lundsten, E. and MeinerJohnson, M. (2011) High-resolution bathymetry of the axial channels within Monterey and Soquel submarine canyons, offshore central California. Geosphere, 75, 1077-1101.

Pickering, K.T. and Hiscott, R.N. (1985) Contained (reflected) turbidity currents from the Middle Ordovician Cloridorme Formation, Quebec Canada: An alternative to the antidune hypothesis. Sedimentology, 32, 373-394.

Postma, G., Roep, T.B. and Ruegg, G.H.J. (1983) Sandygravelly mass-flow deposits in an ice-marginal lake (Saalian, Leuvenumsche Beek valley, Veluwe, the Netherlands), with emphasis on plug-flow deposits. Sed. Geol., 34, 59-82.

Postma, G., Cartigny, M.J.B. and Kleverlaan, K. (2009) Structureless, coarse-tail graded Bouma Ta formed by internal hydraulic jump of the turbidity current? Sed. Geol., 219, 1-6.

Prave, A.R. and Duke, W.L. (1990) Small-scale hummocky crossstratification in turbidites: A form of antidune stratification? Sedimentology, 37, 531-539.

Rajaratnam, N. (1967) Hydraulic jumps. Adv. Hydrosci., 4, 197-280. 
Robertson, J.M. and Rouse, H. (1941) On the four regimes of open-channel flow. Civ. Eng. (N.Y.), 11, 169-171.

Røe, S.L. (1987) Cross-strata and bedforms of probable transitional dune to upper-stage plane-bed origin from a Late Precambrian fluvial sandstone, northern Norway. Sedimentology, 34, 89-101.

Russell, H.A.J. and Arnott, R.W.C. (2003) Hydraulic jump and hyperconcentrated flow deposits of a glacigenic subaqueous fan: Oak Ridges Moraine, southern Ontario, Canada. J. Sed. Res., 73, 887-905.

Russell, H.A.J., Sharpe, D.R. and Bajc, A.F. (2007) Sedimentary signatures of the Waterloo Moraine, Ontario, Canada. In: Glacial Sedimentary Processes and Products (Eds M.J. Hambrey, P. Christoffersen, N.F. Glasser and B. Hubbard), Int. Assoc. Sedimentol. Spec. Publ., 39, 85-108.

Saunderson, H.C. (1982) Bed form diagrams and the interpretation of Eskers. In: Research in Glacial, GlacioFluvial Adn Glacio-Lacustrine Systems (Eds R. DavidsonArnott, W. Nickling and B.D. Fahey), pp. 139-150. Geo Books, Norwich.

Saunderson, H.C. and Lockett, F.P. (1983) Flume experiments on bedforms and structures at the dune-plane bed transition. In: Modern and Ancient Fluvial Systems (Eds J.D. Collinson and J. Lewin), Int. Assoc. Sedimentol. Spec. Publ., 6, 49-58.

Schmincke, H.U., Fisher, R.V. and Waters, A.C. (1973) Antidune and chute and pool structures in the base surge deposits of Laacher See area, Germany. Sedimentology, 20, 553-574.

Schumm, S.A., Bean, D.W. and Harvey, M.D. (1982) Bedform-dependent pulsating flow in Medano Creek, Southern Colorado. Earth Surf. Proc. Landf., 7, 17-28.

Simons, D.B. and Richardson, E.V. (1966) Resistance to Flow in Alluvial Channels. US Geol. Surv. Prof. Pap., 422J, $61 \mathrm{pp}$.

Simons, D. B., Richardson, E. V. and Nordin, C. F. (1965) Sedimentary structures generated by flow in alluvial channels. In: Primary Sedimentary Structures and Their Hydrodynamic Interpretation (Ed. G.V. Middleton), SEPM Spec. Publ., 12, 34-52.

Sisavath, E., Babonneau, N., Saint-Ange, F., Bachèlery, P., Jorry, S.J., Deplus, C., De Voogd, B. and Savoye, B. (2011) Morphology and sedimentary architecture of a modern volcaniclastic turbidite system: The Cilaos fan, offshore La Réunion Island. Mar. Geol., 2881, 1-17.

Sohn, Y.K. (1997) On traction carpet sedimentation. J. Sed. Res., 67, 502-509.

Southard, J.B. and Boguchwal, L.A. (1990) Bed configurations in steady unidirectional flows: Part 2. Synthesis of flume data. J. Sed. Petrol., 60, 658-679.

Southard, J.B., Lambie, J.M., Federico, D.C., Pile, H.T. and Weidman, C.R. (1990) Experiments on bed configurations in fine sands under bidirectional purely oscillatory flow, and the origin of hummocky cross-stratification. J. Sed. Petrol., 60, 1-17.

Spinewine, B., Sequeiros, O.E., Garcia, M.H., Beaubouef, R.T., Sun, T., Svoye, B. and Parker, G. (2009) Experiments on wedge-shaped deep sea sedimentary deposits in minibasins and/or on channel levees emplaced by turbidity currents. Part II. Morphodynamic evolution of the wedge and of the associated bedforms. J. Sed. Res., 79, 608-628.

Straub, K.M. and Mohrig, D. (2009) Constructional canyons built by sheet-like turbidity currents: Observations from offshore Brunei Darussalam. J. Sed. Res., 79, 24-39.
Sumner, E.J., Amy, L.A. and Talling, P.J. (2008) Deposit structure and processes of sand deposition from decelerating sediment suspensions. J. Sed. Res. 78(8), 529-547.

Taki, K. and Parker, G. (2005) Transportational cyclic steps created by flow over an erodible bed. Part 1. Experiments. J. Hydraul. Res., 43, 488-501.

Tinterri, R. (2011) Combined flow sedimentary structures and the genetic link between sigmoidal- and hummockycross stratification. GeoActa, 10, 1-43.

Van den Berg, J.H. and Nio, S.D. (2010) Sedimentary Structures and their Relation to Bedforms and Flow Conditions. EAGE Publications, Houten, 138 pp.

Van den Berg, J.H. and Van Gelder, A. (1993) A new bedform stability diagram, with emphasis on the transition of ripples to plane bed in flows over fine sands and silt. In: Alluvial Sedimentation (Eds M. Marzo and C. Puigdefabregas), Int. Ass. Sed. Spec. Publ., 17, 11-21.

Van den Berg, J.H. and Van Gelder, A. (1998) Discussion: Flow and sediment transport over large subaqueous dunes: Fraser River, Canada. Sedimentology, 45, 217-221.

Van den Berg, J.H., Boersma, J.R. and Van Gelder, A. (1997) Diagnositc sedimentary structures of the fluvial-tidal transition zone - Evidence form deposits of the Rhine and Meuse. Geol. Mijnbouw, 86, 287-306.

Van den Berg, J.H., Van Gelder, A. and Mastbergen, D.R. (2002) The importance of breaching as a mechanism of subaqueous slope failure in fine sand. Sedimentology, 49, 81-95.

Van Rhee, C. and Bezuijen, A. (1998) The breaching of sand investigated in large-scale model tests. Proceedings of the International Coastal Engineering Conference, Copenhagen. Am. Soc. Civ. Eng., 3, 2509-2519.

Van Rijn, L.C. (1984a) Sediment transport, Part I: Bed load transport. J. Hydraul. Eng ASCE, 110, 1431-1456.

Van Rijn, L.C. (1984b) Sediment transport, Part III: Bed forms and alluvial roughness. J. Hydraul. Eng. ASCE, 110, 1733-1754.

Vanoni, V.A. (1974) Factors determining bed forms of alluvial stream. J. of Hydr. Div, 100(3), 363-377.

Vedernikov, V.V. (1945) Conditions at the front of a translation wave disturbing a steady motion of real fluid. Dokl. Acad. Sci. USSR, 48, 239-242.

Vedernikov, V.V. (1946) Characteristic features of a liquid flow in open channel. Dokl. Acad. Sci. USSR, 52, 207-210.

Venditti, J.G., Church, M. and Bennett, S.J. (2006) On interfacial instability as a cause of transverse subcritical bed forms. Water Resour. Res., 427, W07423.

Waters, A.C. and Fisher, R.V. (1971) Base surges and their deposits: Capelinhos and Taal volcanoes. J. Geophys. Res., 76, 5596-5614.

Welch, P.D. (1967) The use of fast fourier transform for the estimation of power spectra: A method based on time averaging over short, modified periodograms. IEEE Trans. Audio and Electro., 15, 70-73.

Wells, S.G. and Dohrenwend, J.C. (1985) Relict sheetflood bed forms on late Quaternary alluvial-fan surfaces in the southwestern United States. Geology, 13, 512-516.

Winterwerp, J.C., Bakker, W.T., Mastbergen, D.R. and Van Rossum, H. (1992) Hyperconcentrated sand-water mixture flows over erodible bed. J. Hydraul. Engin., 118, 1508-1525.

Yagishita, K. (1992) Recent studies on some sedimentary structures formed under upper-flow-regime conditions: Review and discussion. Ann. Rep. Fac. Educ. Iwate Univ., 52, 85-95. 
Yagishita, K., Ashi, J., Ninomiya, S. and Taira, A. (2004) Two types of plane beds under upper-flow-regime in flume experiments: Evidence from grain fabric. Sed. Geol., 163, 229-236.

Yokokawa, M., Okuno, K., Nakamura, A., Muto, T., Miyata, Y. and Naruse, H. (2009) Aggradational cyclic steps: Sedimentary structures found in flume experiments. Proceedings 33rd IAHR Congress, Vancouver, pp. 55475554.

Yokokawa, M., Hasegawa, K., Kanbayashi, S. and Endo, N. (2010) Formative conditions and sedimentary structures of sandy 3D antidunes: An application of the gravel steppool model to fine-grained sand in an experimental flume. Earth Surf. Proc. Landf., 35, 1720-1729.

You, Y., Flemming, P. and Mohrig, D. (2012) Dynamics of dilative slope failure. Geology, 407, 663-666.

Zhou, D. and Mendoza, C. (2005) Growth model for sand wavelets. J. Hydraul. Eng., 13110, 866-876.

Manuscript received 2 December 2011; revision accepted 1 August 2013

\section{Supporting Information}

Additional Supporting Information may be found in the online version of this article:

Movie S1. Comparison between the direct observations and the synthetic architecture for stable antidunes.

Movie S2. Comparison between the direct observations and the synthetic architecture for unstable antidunes.

Movie S3. Comparison between the direct observations and the synthetic architecture for chutesand-pools.

Movie S4. Comparison between the direct observations and the synthetic architecture for cyclic steps. 